\title{
Expert consensus guidelines: Examining surgical ablation for atrial fibrillation
}

\author{
Niv Ad, MD, ${ }^{\text {a,b }}$ Ralph J. Damiano, Jr, MD, ${ }^{\mathrm{c}}$ Vinay Badhwar, MD, ${ }^{\mathrm{a}}$ Hugh Calkins, MD, ${ }^{\mathrm{d}}$ \\ Mark La Meir, MD, ${ }^{\mathrm{e}}$ Takashi Nitta, MD, PhD, ${ }^{\mathrm{f}}$ Nicolas Doll, MD, ${ }^{\mathrm{g}}$ Sari D. Holmes, PhD, ${ }^{\mathrm{h}}$ \\ Ali A. Weinstein, $\mathrm{PhD},{ }^{\mathrm{i}}$ and Marc Gillinov, $\mathrm{MD}^{\mathrm{j}}$
}

\footnotetext{
From the ${ }^{\mathrm{a} D e p a r t m e n t}$ of Cardiovascular and Thoracic Surgery, and ${ }^{\mathrm{h}}$ WVU Heart and Vascular Institute, West Virginia University Morgantown, WVa; ${ }^{\text {b} W a s h i n g t o n ~ A d v e n t i s t ~ H o s p i t a l, ~ A d v e n t i s t ~ H e a l t h C a r e, ~ T a k o m a ~}$ Park, Md; ' Division of Cardiothoracic Surgery, Department of Surgery, Washington University School of Medicine at Barnes-Jewish Hospital, St Louis, Mo; ${ }^{\mathrm{d} D i v i s i o n}$ of Cardiology, Department of Medicine, Johns Hopkins University School of Medicine, Baltimore, Md; ${ }^{e}$ Department of Cardiothoracic Surgery, Academic Hospital Maastricht, Maastricht, The Netherlands; ${ }^{\mathrm{f} D e p a r t m e n t}$ of Cardiovascular Surgery, Nippon Medical

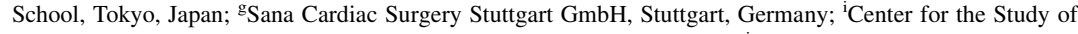
Chronic Illness and Disability, George Mason University, Fairfax, Va; and ${ }^{\mathrm{j} D e p a r t m e n t}$ of Thoracic and Cardiovascular Surgery, The Cleveland Clinic, Cleveland, Ohio.

Received for publication Dec 21, 2016; revisions received Jan 27, 2017; accepted for publication Feb 1, 2017; available ahead of print April 5, 2017

Address for reprints: Niv Ad, MD, Department of Cardiovascular and Thoracic Surgery, West Virginia University School of Medicine, 1 Medical Center Drive, Morgantown, WV 26506 (E-mail: nivadmd14@gmail.com).

J Thorac Cardiovasc Surg 2017;153:1330-54

$0022-5223 / \$ 36.00$

Copyright (c) 2017 by The American Association for Thoracic Surgery

http://dx.doi.org/10.1016/j.jtcvs.2017.02.027
}

f Supplemental material is available online.

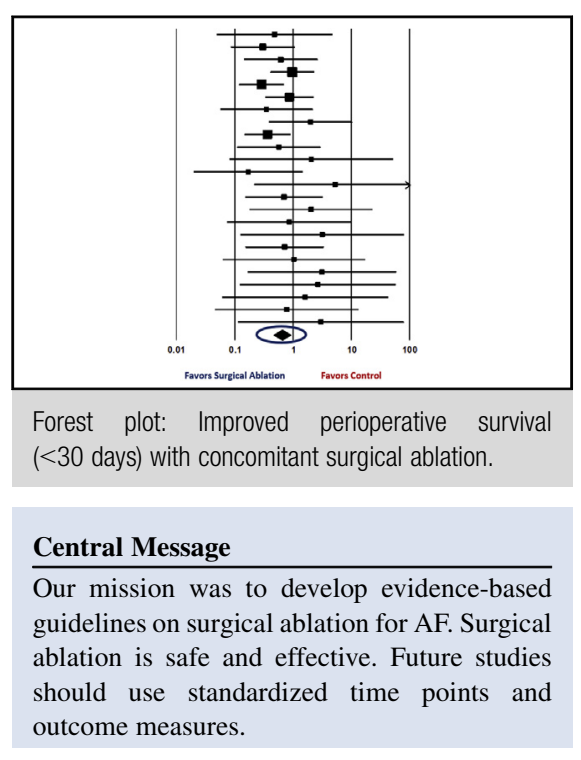

See Editorial Commentary page 1355.

\section{EXECUTIVE SUMMARY}

Research Question 1: Does concomitant surgical ablation for atrial fibrillation (AF) increase the incidence of perioperative morbidity?

Recommendation \#1. Addition of a concomitant surgical ablation procedure for AF does not increase the incidence of perioperative morbidity.

Class IIa: It is reasonable to choose to perform a concomitant surgical ablation procedure for patients with a history of AF over no treatment of AF because the incidence of perioperative morbidity is not increased by surgical ablation.

Level of Evidence:

- Level A for deep sternal wound infection, pneumonia, reoperation for bleeding, and renal failure requiring dialysis

- Level B-R for intensive care unit length of stay and total hospital length of stay

- Level B-NR for readmission less than 30 days and renal failure

Research Question 2A: Does concomitant surgical ablation for $\mathrm{AF}$ reduce the incidence of perioperative stroke/transient ischemic attack (TIA)?
Recommendation \#2. Addition of a concomitant surgical ablation procedure for AF does not change the incidence of perioperative stroke/TIA.

Class IIa: It is reasonable to choose to perform a concomitant surgical ablation procedure for patients with a history of AF over no treatment of $\mathrm{AF}$ because there is no increased risk of perioperative stroke/TIA.

Level of Evidence: Level A

Research Question 2B. Does concomitant surgical ablation for $A F$ reduce the incidence of late stroke/TIA?

Recommendation \#3. Overall, addition of a concomitant surgical ablation procedure for AF does not change the incidence of late stroke/TIA, but subgroup analysis of nonrandomized controlled trials found a significant reduction in late stroke/TIA incidence.

Class IIa: It is reasonable to choose to perform a concomitant surgical ablation procedure for patients with a history of AF over no treatment of AF because the incidence of late stroke/TIA is unaffected or decreased by surgical ablation. 
Level of Evidence:

- Level A for no change in incidence of late strokel TIA (up to 1 year of follow-up after surgery)

- Level B-NR for reduction in incidence of late stroke/TIA (>1 year of follow-up after surgery)

Research Question 3. Does concomitant surgical ablation for AF improve health-related quality of life (HRQL) and AF-related symptoms?

Recommendation \#4. A surgical procedure that includes concomitant surgical ablation for AF does improve HRQL. Addition of concomitant surgical ablation for AF does improve AF-related symptoms, and this improvement is greater than in patients without surgical ablation for AF.

Class IIa: It is reasonable to choose to perform a concomitant surgical ablation procedure for patients with a history of AF over no treatment of AF because there is significant improvement in HRQL and AF-related symptoms associated with surgical ablation for AF.

Level of Evidence:

- Level B-R for HRQL

- Level C-LD for AF-related symptoms

Research Question 4A: Does concomitant surgical ablation for AF improve short-term survival?

Recommendation \#5. Addition of concomitant surgical ablation for AF does improve 30-day operative mortality.

Class I: It is recommended to choose to perform a concomitant surgical ablation procedure for patients with a history of AF over no treatment of AF because there is significant improvement in operative survival associated with surgical ablation.

Level of Evidence: Level A

Research Question 4B: Does concomitant surgical ablation for AF improve long-term survival ( $>30$ days)?

Recommendation \#6. Overall, addition of a concomitant surgical ablation procedure for AF improves longterm survival.

Class IIa: It is reasonable to choose to perform a concomitant surgical ablation procedure for patients with a history of AF over no treatment of AF because long-term survival is unaffected or improved by surgical ablation.

Level of Evidence:

- Level A for no change in long-term survival (up to 1 year after surgery)
- Level B-NR for improvement in long-term survival (>1 year after surgery)

Research Question 5: What are the indications for a hybrid ablation or stand-alone off-pump epicardial ablation in patients with AF?

Recommendation \#7. Overall, hybrid procedures have shown promising results compared with percutaneous catheter ablation in a subgroup of symptomatic patients with $\mathrm{AF}$ in whom medical treatment or percutaneous catheter ablation have failed.

Class IIb: Hybrid procedures may be considered as a stand-alone procedure in patients with appropriate indications and by an experienced heart team.

Level of Evidence: Level B-NR

Recommendation \#8. Overall, minimally invasive approaches to isolate the pulmonary veins bilaterally have shown promising results compared with percutaneous catheter ablation in a subgroup of symptomatic patients with paroxysmal $\mathrm{AF}$ and a small left atrium in whom medical treatment or percutaneous catheter ablation has failed.

Class IIa: It is reasonable to perform stand-alone surgical ablation for pulmonary vein isolation in patients with symptomatic paroxysmal $\mathrm{AF}$ and small left atria.

Level of Evidence: Level B-R

Research Question 6: Which surgical ablation devices are associated with reliable transmural lesions?

Recommendation \#9. The best evidence exists for the use of bipolar radiofrequency (RF) clamps and cryoablation devices, which have become integral parts of many procedures, including pulmonary vein isolation and the Cox-Maze IV procedure. The use of epicardial unipolar RF ablation outside of clinical trials is not recommended, because its efficacy remains questionable.

a. Empty arrested or beating heart: Recommended ablation devices for pulmonary vein isolation are bipolar $\mathrm{RF}$ clamps or reusable/disposable cryoprobes.

b. Beating heart: Bipolar RF clamps are effective to isolate pulmonary veins and recommended with mandatory testing for exit or entrance block.

c. Beating heart: Surface bipolar RF devices may be recommended for free wall linear ablation when lesion integrity can be tested and multiple applications are recommended to achieve adequate lesion depth.

d. Beating heart: Epicardial cryoablation is not recommended, but endocardial cryoablation is 
recommended for free wall linear ablation because of the high degree of transmurality.

e. Clinical trials of hybrid procedures: only settings where epicardial unipolar RF or unidirectional bipolor RF devices may be applied provided it is accompanied by acute lesion integrity testing.

f. When ablating with any device, coronary arteries should be identified and avoided.

\section{Research Question 7: What is the impact of surgeon experience with surgical ablation on return to sinus rhythm in patients with AF?}

Recommendation \#10. Training and education should be completed before the performance of surgical ablation. We highly recommend surgeons who are new to surgical AF be proctored by an experienced surgeon for 3 to 5 cases before performing surgical ablation alone.

Class I: Training and education should be considered before the performance of surgical ablation, but the effectiveness of a training program is unclear. More specific research needs to be conducted because there have been limited populations evaluated.

Level of Evidence: Level C

\section{TABLE OF CONTENTS}

Introduction . . . . . . . . . . . . . . . . . . . . . 1332

Preamble . . . . . . . . . . . . . . . . . . . . . . . . 1333

Methods of Review . . . . . . . . . . . . . . . . 1333

Target Audience and the Patient Population . . . . . . . 1335

Epidemiology of Atrial Fibrillation and Its Impact on

Outcomes, Cost, and Morbidity . . . . . . . . . . . . . . . 1335

Recommendations and Reasoning . . . . . . . . . 1335

AIM 1. Safety and Efficacy of Surgical Ablation . . . . . 1335

Reasoning . . . . . . . . 1336, 1338-1339, 1341-1343

AIM 2. Indications for Surgical Ablation Using Hybrid

Approaches . . . . . . . . . . . . . . . . . . . . 1343

Reasoning . . . . . . . . . . . . . . . . . . 1344

Bilateral pulmonary vein isolation and

management of left atrial appendage . . . . . . . 1346

Unilateral thoracoscopic pulmonary vein isolation

encircling lesion without left atrial appendage

exclusion . . . . . . . . . . . . . . . . . . 1347

Epicardial pericardioscopic posterior left atrial ablation ("convergent procedure") without left atrial appendage exclusion . . . . . . . . . . . 1347

AIM 3. Ablation Tools. . . . . . . . . . . . . . . . . . . . 1347

Reasoning . . . . . . . . . . . . . . . 1347-1348

Bipolar radiofrequency clamps . . . . . . . . . . . 1348

Surface bipolar devices. . . . . . . . . . . . . . . . 1348

Unipolar radiofrequency devices . . . . . . . . . . 1348

Cryoablation devices . . . . . . . . . . . . . . 1349

AIM 4. Training . . . . . . . . . . . . . . . . . . . . . . . 1349

Reasoning . . . . . . . . . . . . . . . . . . . 1349

Risks associated with untreated atrial fibrillation . 1349
Risks associated with treating atrial fibrillation . . 1349

Recommended ablation procedure . . . . . . . 1350

Results of surgical ablation . . . . . . . . . . . 1350

Recommendations for Future American Association for

Thoracic Surgery Efforts . . . . . . . . . . . . . . . . 1350

Recommendations for the Use of the Guidelines. . . . . . 1351

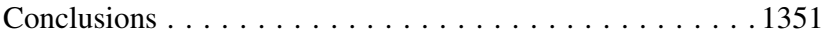

Conflict of Interest Statement . . . . . . . . . . . . . . . 1351

References . . . . . . . . . . . . . . . . . . . 1351

\section{INTRODUCTION}

The surgical treatment for atrial fibrillation (AF) is well established and performed. AF is being treated as a stand-alone procedure or concomitantly with valve, coronary bypass, or other types of cardiac surgical procedures. This document was put together to serve as guidelines and provide recommendations related to the general outcomes associated with surgical ablation, the state of hybrid procedures, the optimal ablation tools available, and the recommendations for the appropriate education and training of surgeons in the field.

The Cox-Maze procedure was first performed in 1987 by Dr James L. Cox, and the report summarizing the experience with the Cox-Maze I procedure was published in $1991 .^{1}$ The original Cox-Maze was performed as a cut-and-sew procedure combined with focal cryoablations in both the right atrium and the left atrium (LA) and evolved from the Cox-Maze I to III to address issues with sinus node function and right-to-left atrial conduction that resulted from the Cox-Maze I. ${ }^{2}$ The Cox-Maze III procedure was then applied extensively in clinical practice. ${ }^{3}$

Several modifications to the original lesion set have been introduced, as well as the introduction of surgical ablation tools that use different energy sources (Figure 1). ${ }^{4,5}$ These different energy sources were applied to perform lesion sets confined to the LA pulmonary vein isolation only, a more extensive lesion set, or a full right and left atrial lesion set. ${ }^{6-8}$ Despite the proven success of the Cox-Maze procedure and surgical ablation, referring general surgeons and physicians remain somewhat reluctant to adopt the procedure. A clear difference was documented for surgeon experience in the percentage of patients with AF treated concomitantly during cardiac surgical procedures. ${ }^{9}$ The explanation for such a unique phenomenon in the surgical practice is not easy, but probably is due to the perceived risk associated with the procedure, the level of training of the surgeons, and the lack of recognition of the clinical importance of AF.

These The American Association for Thoracic Surgery (AATS) guidelines are focused less on the efficacy of surgical ablation and more on the surgical outcomes, both in the short term and the long term. We also addressed the hybrid surgical ablation procedures that are performed together by electrophysiologists and cardiac surgeons. 
These new procedures may add to our ability to treat patients with AF successfully.

It is clear that the success of any ablation procedure is dependent on the lesion pattern and the quality of the lesion. Surgeons should be familiar with the different lesion set options and the efficacy of the ablation tool in use.

The AATS committee was tasked with the following:

I. To present a current analysis of the published literature and present a balanced view

II. To provide evidence-based clinical practice recommendations

III. To address the quality and the effectiveness of the different energy sources

IV. To discuss the education and training requirement for surgeons who are performing surgical ablation procedures

\section{PREAMBLE}

Our mission was to develop evidence-based guidelines on surgical ablation for the treatment of AF. Ten experts were invited by the AATS leadership to participate in this effort: 7 cardiac surgeons, 1 electrophysiologist, and 2 biostatisticians.

\section{Methods of Review}

Members were tasked with making recommendation on the basis of a a review of the literature and meta-analyses of the literature (if it was possible). The task force panel graded the class of recommendation and the level of evidence for each of the research questions/recommendations according to the standards published by the Institute of Medicine. The 5 different classes of recommendation are Class I (strong), IIa (moderate), IIb (weak), III (no benefit, moderate), and Class III (harm, strong). The 5 levels of evidence are Level A, B-R (randomized), B-NR (nonrandomized), C-LD (limited data), and Level C-EO (expert opinion).

Meta-analyses were conducted to investigate the 4 research questions within Aim 1 (safety and efficacy of surgical ablation). Relevant studies were identified through an electronic search of PubMed using comprehensive search terms for each of the relevant study questions (Table E1). Reference lists of selected articles were reviewed for other potentially relevant citations as needed. The study period was confined from January 2000 to December 2015. Inclusion criteria comprised studies with concomitant surgical ablation procedures (full lesion set or limited) in the adult human population and a comparison group present. Only English language studies were included. There were no criteria limiting the type of lesion set performed or energy source used. Therefore, the included studies were variable on these components of surgical ablation.

\section{Left Atrial Lesion Set}

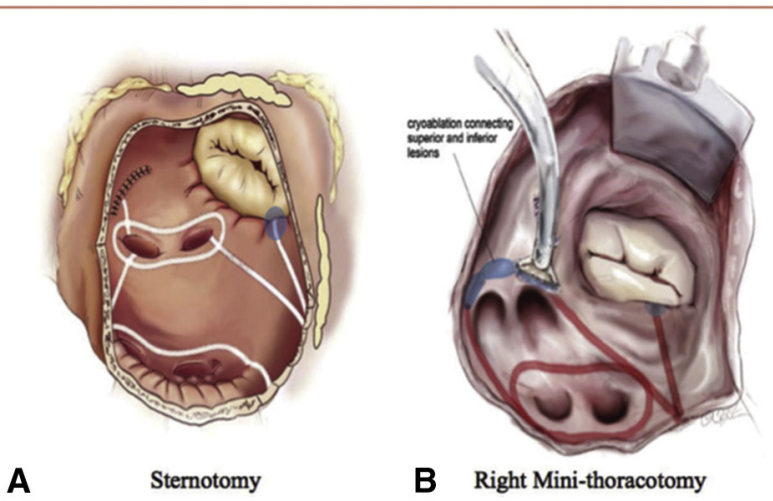

Right Atrial Lesion Set
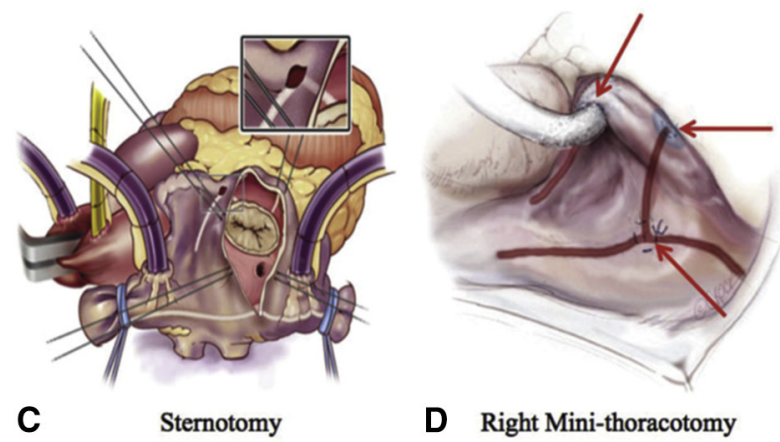

D Right Mini-thoracotomy

FIGURE 1. Left atrial lesion sets for Cox-Maze IV procedure. A, Most linear lesions are created with bipolar RF clamps; shaded in blue are cryolesions at the mitral isthmus (and left pulmonary veins for minimally invasive approach). B, Linear lesions also can be created with cryoablation if required for minithoracotomies or reoperations. Right atrial lesion sets for Cox-Maze IV procedure. C, Most linear lesions are created with bipolar RF clamps, and cryolesions are placed at 2 points on the tricuspid annulus through direct vision or small purse-string sutures (red arrows). D, Linear lesions also can be created with cryoablation if required for minithoracotomies or reoperations. (Reprinted from Badhwar V, Rankin JS, Damiano RJ Jr, Gillinov AM, Bakaeen FG, Edgerton JR, et al. The Society of Thoracic Surgeons 2017 Clinical Practice Guidelines for the Surgical Treatment of Atrial Fibrillation. Ann Thorac Surg. 2017;103: 329-41. (c) [2014] Beth Croce).

For Research Question 1 ("Does concomitant surgical ablation for $\mathrm{AF}$ increase the incidence of perioperative morbidity?"), the outcome was operationalized as complications, excluding stroke and mortality within 30 days of surgery because these outcomes were examined in separate research questions. The following complications were included: deep sternal wound infection, pneumonia, reoperation for bleeding, renal failure, renal failure requiring dialysis, readmission less than 30 days, length of stay in the intensive care unit (ICU), and total hospital length of stay. A total of 905 studies were identified from the original PubMed search, of which 300 were reviewed in depth for inclusion, and 27 studies ultimately met all 
SIZE OF TREATM E T EFFECT

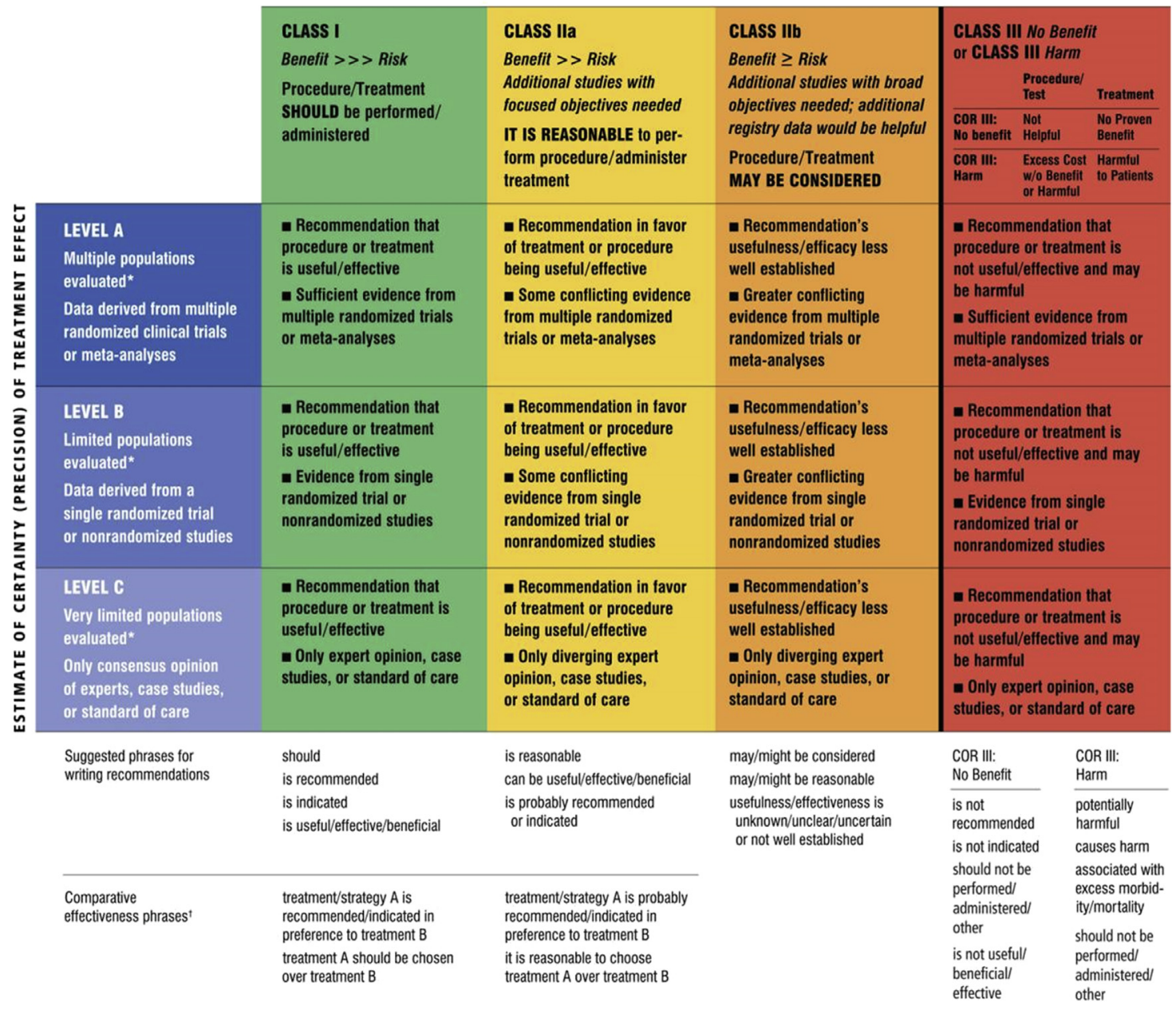

FIGURE 2. Classification of recommendations and level of evidence using the American College of Cardiology/American Heart Association grading schema.

inclusion criteria. ${ }^{10-36}$ The remaining 273 studies were excluded because of no comparison group $(n=245)$, case report $(n=7)$, no outcome data $(n=17)$, or duplicate data from the same investigators $(n=4)$.

For Research Question 2 ("Does concomitant surgical ablation for AF impact the incidence of perioperative and late stroke/transient ischemic attack [TIA]?"), the outcome was separated into perioperative (in-hospital or $<30$ days) stroke and late or follow-up stroke. A total of 614 studies were identified through the PubMed search, and an additional 20 studies were identified through review of reference lists of other articles. Of these studies, 87 were reviewed in depth for inclusion, and 20 ultimately met all inclusion criteria. $^{13,18,22-24,26-28,30-33,35-42}$ The remaining 67 studies were excluded because of no comparison group $(\mathrm{n}=23)$, catheter ablation rather than surgical ablation $(\mathrm{n}=17)$, duplicate data $(\mathrm{n}=10)$, no ablation $(\mathrm{n}=7)$, reviews $(n=6)$, and no outcome data $(n=4)$.

For Research Question 3 ("Does concomitant surgical ablation for $\mathrm{AF}$ improve health-related quality of life
[HRQL] and AF-related symptoms?"), a standard meta-analysis was not feasible because of heterogeneity in methods, postoperative time points, and measures among studies. Therefore, a systematic review of the relevant studies was undertaken instead, which also allowed for inclusion of studies with no comparison group on these outcomes. From a total of 222 studies found through a PubMed search, 9 were selected for inclusion in the systematic review. ${ }^{10,24,33,39,43-47}$ These included 4 randomized control trial (RCT) studies, 2 non-RCT studies, and 3 studies with no control group. All studies examined HRQL, and 4 of the studies also investigated symptom status.

For Research Question 4 ("Does concomitant surgical ablation for $\mathrm{AF}$ improve perioperative and long-term survival?"), the outcome was separated into short-term ( $<30$ days) and long-term $(\geq 12$ months) mortality. A total of 905 studies were identified from the original PubMed search, of which 300 were reviewed in depth for inclusion, and 38 studies ultimately met all inclusion 
TABLE 1. Level of evidence and classification summary for each recommendation

\begin{tabular}{|c|c|c|}
\hline Recommendation & Class & Level \\
\hline \multicolumn{3}{|l|}{ \#1: Perioperative morbidity } \\
\hline $\begin{array}{l}\text { DSWI, pneumonia, bleeding reoperation, } \\
\text { RF with dialysis }\end{array}$ & IIa & Level A \\
\hline ICU stay, total LOS & IIa & Level B-R \\
\hline Readmission $<30 \mathrm{~d}, \mathrm{RF}$ & IIa & Level B-NR \\
\hline \#2: Perioperative stroke/TIA & IIa & Level A \\
\hline \multicolumn{3}{|l|}{ \#3: Late stroke/TIA } \\
\hline Up to 1-y follow-up & IIa & Level A \\
\hline$>1-y$ follow-up & IIa & Level B-NR \\
\hline \multicolumn{3}{|l|}{ \#4: Quality of life } \\
\hline HRQL & IIa & Level B-R \\
\hline AF-related symptoms & IIa & Level C-LD \\
\hline \#5: Short-term survival & I & Level A \\
\hline \multicolumn{3}{|l|}{ \#6: Long-term survival } \\
\hline Up to 1-y follow-up & IIa & Level A \\
\hline$>1-y$ follow-up & IIa & Level B-NR \\
\hline \#7: Hybrid ablation & $\mathrm{IIb}$ & Level B-NR \\
\hline \#8: Stand-alone off-pump epicardial ablation & IIa & Level B-R \\
\hline \#9: Surgical ablation device transmurality & N/A & N/A \\
\hline \#10: Surgeon experience & I & Level C \\
\hline
\end{tabular}

$D S W I$, Deep sternal wound infection; $R F$, radiofrequency; $I C U$, intensive care unit; $L O S$, length of stay; TIA, transient ischemic attack; $H R Q L$, health-related quality of life; $A F$, atrial fibrillation; $N / A$, not available.

criteria. $^{10-20,22-36,40,42,48-57}$ The remaining 262 studies were excluded because of no comparison group $(n=245)$, case report $(n=7)$, no outcome $(n=6)$, or duplicate data from the same investigators $(n=4)$.

All meta-analyses were conducted using Comprehensive Meta-Analysis Version 2.2.064 (Biostat, Inc, Englewood, NJ). Effect sizes were able to be generated from studies with various outcome data presentations to combine the most studies possible for each question. Heterogeneity for each outcome was tested using Cochran's Q value and the $\mathrm{I}^{2}$ statistic. Analyses with significant levels of heterogeneity were conducted using random effects models, whereas all other analyses were conducted using fixed-effects modeling. Forest plots were generated for each outcome and separately for RCT and non-RCT studies when necessary, which was identified as the most common source of heterogeneity for these analyses.

For Aims 2, 3, and 4, meta-analyses were not possible on the basis of the current state of the literature. For these aims, literature summaries were conducted for each respective aim. Aim 3, which focuses on the evidence for devices, will not have class or level of evidence because the literature is based on animal data and is too unique for systematic combination. Then these summaries were submitted for full task force review and consideration. A consensus among the task force members was achieved before the adoption of the recommendations.
A final draft was prepared by authors N.A. and S.D.H., and this written draft was distributed to all members of the task force for final comments.

The following recommendations are based on the best available evidence from ablation surgery literature. This literature is relatively small in some areas, and at those points, expert opinion was substituted for research literature to make recommendations. The recommendations are classified according to the American Heart Association/ American College of Cardiology schema ${ }^{58}$ (Figure 2), and a summary of each can be found in Table 1.

\section{Target Audience and the Patient Population}

These guidelines are intended for cardiothoracic surgeons performing operations in patients with $\mathrm{AF}$, as well as cardiologists and electrophysiologists who refer patients for surgical intervention.

\section{EPIDEMIOLOGY OF ATRIAL FIBRILLATION AND ITS IMPACT ON OUTCOMES, COST, AND MORBIDITY}

AF currently affects approximately 2.2 million patients in the United States, and this figure is projected to at least double in the next 25 years. ${ }^{59}$ Approximately $2 \%$ of those aged less than 65 years have $\mathrm{AF}$, and that number increases to approximately $9 \%$ in those aged more than 65 years. ${ }^{60}$ African-Americans are less likely to experience AF than those of European descent.

AF has a direct relationship to mortality and increased morbidity, especially for risk of stroke. Specifically, AF is associated with a 1.5 to 1.9 increase in mortality risk, even after adjustment for many potential confounding variables, including preexisting cardiovascular conditions. ${ }^{61}$ The age-adjusted incidence of stroke is 5 times greater when $\mathrm{AF}$ is present. ${ }^{62}$ Hospitalizations with $\mathrm{AF}$ as the primary diagnosis exceed 460,000 each year, and the hospitalization is the primary cost driver in the management of AF. ${ }^{63}$ Medical costs are higher (73\% higher) in those with $\mathrm{AF}$ than in matched individuals without $\mathrm{AF}$, with approximately 6 billion dollars in medical costs spent on AF-related costs alone. ${ }^{63}$

\section{RECOMMENDATIONS AND REASONING}

AIM 1. Safety and Efficacy of Surgical Ablation

Research Question 1: Does concomitant surgical ablation for AF increase the incidence of perioperative morbidity?

Recommendation \#1. Addition of a concomitant surgical ablation procedure for AF does not increase the incidence of perioperative morbidity (Class IIa, Level A for deep sternal wound infection, pneumonia, reoperation for bleeding, and renal failure requiring dialysis, Level B-R for 


\begin{tabular}{|c|c|c|c|c|c|c|c|c|}
\hline \multirow[t]{2}{*}{ Model } & \multirow[t]{2}{*}{ Study name } & \multirow[t]{2}{*}{ Subgroup within study } & \multirow[t]{2}{*}{ Outcome } & \multirow[b]{2}{*}{$\begin{array}{l}\text { Odds } \\
\text { ratio }\end{array}$} & \multicolumn{3}{|c|}{ Statistics for each study } & \multirow[b]{2}{*}{$\mathrm{p}$-Value } \\
\hline & & & & & $\begin{array}{l}\text { Lower } \\
\text { limit }\end{array}$ & $\begin{array}{l}\text { Upper } \\
\text { limit }\end{array}$ & Z-Value & \\
\hline & Yoo & Non-RCT & Pneumonia & 1.490 & 0.091 & 24.385 & 0.280 & 0.780 \\
\hline & $\mathrm{Ad}$ & Non-RCT & Pneumonia & 0.178 & 0.066 & 0.477 & 3.428 & 0.001 \\
\hline & Saint & Non-RCT & Pneumonia & 0.618 & 0.144 & 2.653 & -0.648 & 0.517 \\
\hline & Budera & RCT & Pneumonia & 0.650 & 0.142 & 2.978 & -0.554 & 0.579 \\
\hline & Abreu Filho & RCT & Pneumonia & 2.077 & 0.205 & 21.045 & 0.619 & 0.536 \\
\hline & Liu & RCT & Pneumonia & 0.735 & 0.156 & 3.456 & -0.390 & 0.697 \\
\hline & Boersma & RCT & Pneumonia & 3.149 & 0.126 & 78.801 & 0.698 & 0.485 \\
\hline & Vasconcelos & SRCT & Pneumonia & 0.290 & 0.011 & 7.737 & -0.738 & 0.460 \\
\hline Fixed & & & & 0.474 & 0.262 & 0.857 & -2.472 & 0.013 \\
\hline
\end{tabular}

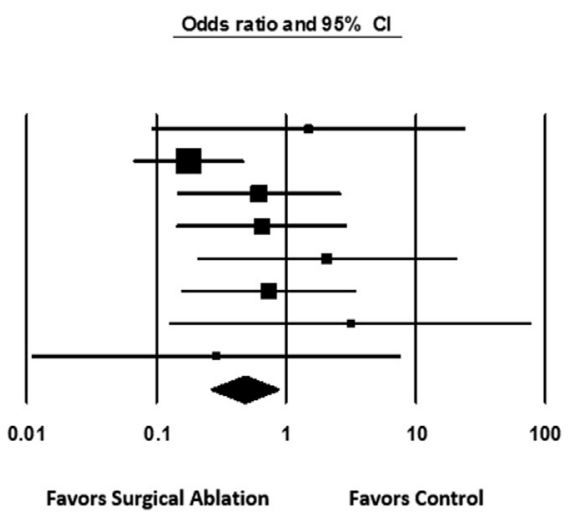

\section{Meta Analysis}

FIGURE 3. Forest plot for pneumonia in the perioperative time frame ( $<30$ days $)$ with concomitant surgical ablation. $C I$, Confidence interval; $R C T$, randomized controlled trial.

ICU length of stay and total hospital length of stay, and Level B-NR for readmission $<30$ days and renal failure).

Reasoning. Overall, the current literature demonstrates a decreased incidence of perioperative morbidity, including reduced incidence of pneumonia in the perioperative time frame and decreased lengths of stay in the ICU. When exclusively examining RCTs, it was also found that total length of stay was increased with concomitant surgical ablation.

The meta-analysis for Research Question 1 investigated the potential increase in morbidity in concomitant surgical ablation examining the following outcome variables: pneumonia, deep sternal wound infection, length of stay in the ICU, total hospital stay, readmissions within 30 days, reoperation for bleeding, renal failure, and renal failure requiring dialysis. The evidence from this meta-analysis indicates that the only perioperative morbidity significantly associated with concomitant surgical ablation for AF was reduced incidence of pneumonia in the perioperative time frame (odds ratio $[\mathrm{OR}], 0.474 ; 95 \%$ confidence interval $[\mathrm{CI}], 0.262-0.857 ; P=.013$ ) (Figure 3). The surgical ablation group had a $53 \%$ reduced odds for perioperative pneumonia. With 5 RCT and 3 non-RCT studies included in this analysis and no significant heterogeneity identified

\begin{tabular}{|c|c|c|c|c|c|c|c|c|}
\hline \multirow[t]{2}{*}{ Mbdel } & \multirow[t]{2}{*}{ Study name } & \multirow[t]{2}{*}{ Subgroup within study } & \multirow[t]{2}{*}{ Outcome } & \multirow[b]{2}{*}{$\begin{array}{l}\text { Odds } \\
\text { ratio }\end{array}$} & \multicolumn{3}{|c|}{ Statistics for each study } & \multirow[b]{2}{*}{ p-Value } \\
\hline & & & & & $\begin{array}{l}\text { Lower } \\
\text { limit }\end{array}$ & $\begin{array}{c}\text { Upper } \\
\text { limit }\end{array}$ & Z-Value & \\
\hline & Saint & Non-RCT & DSWI & 0.346 & 0.014 & 8.592 & -0.647 & 0.517 \\
\hline & Budera & $\mathrm{RCT}$ & DSWI & 4.476 & 0.212 & 94.327 & 0.964 & 0.335 \\
\hline & Kum JB & Non-RCT & DSWI & 0.264 & 0.011 & 6.509 & -0.814 & 0.415 \\
\hline & Abreu Filho & $\mathrm{RCT}$ & DSWl & 2.060 & 0.081 & 52.392 & 0.438 & 0.662 \\
\hline & Nakajima & Non-RCT & DSWl & 8.867 & 0.422 & 186.316 & 1.405 & 0.160 \\
\hline & Doukas & $\mathrm{RCT}$ & DSWI & 0.846 & 0.296 & 2.412 & -0.314 & 0.754 \\
\hline & Liu & RCT & DSWI & 1.361 & 0.289 & 6.397 & 0.390 & 0.697 \\
\hline & Srivastava & $\mathrm{RCT}$ & DSWI & 1.017 & 0.041 & 25.457 & 0.010 & 0.992 \\
\hline & Albrecht & $\mathrm{RCT}$ & DSWI & 1.557 & 0.061 & 39.945 & 0.267 & 0.789 \\
\hline Fixed & & & & 1.133 & 0.561 & 2.288 & 0.348 & 0.728 \\
\hline
\end{tabular}

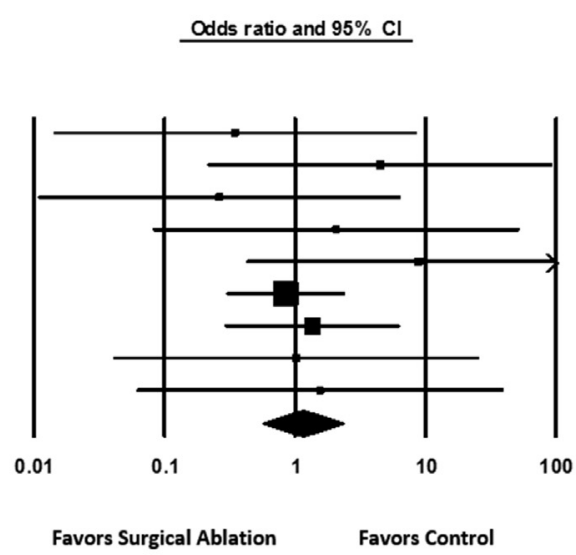

Meta Analysis

FIGURE 4. Forest plot for deep sternal wound infection in the perioperative time frame ( $<30$ days $)$ with concomitant surgical ablation. $C I$, Confidence interval; $R C T$, randomized controlled trial. 


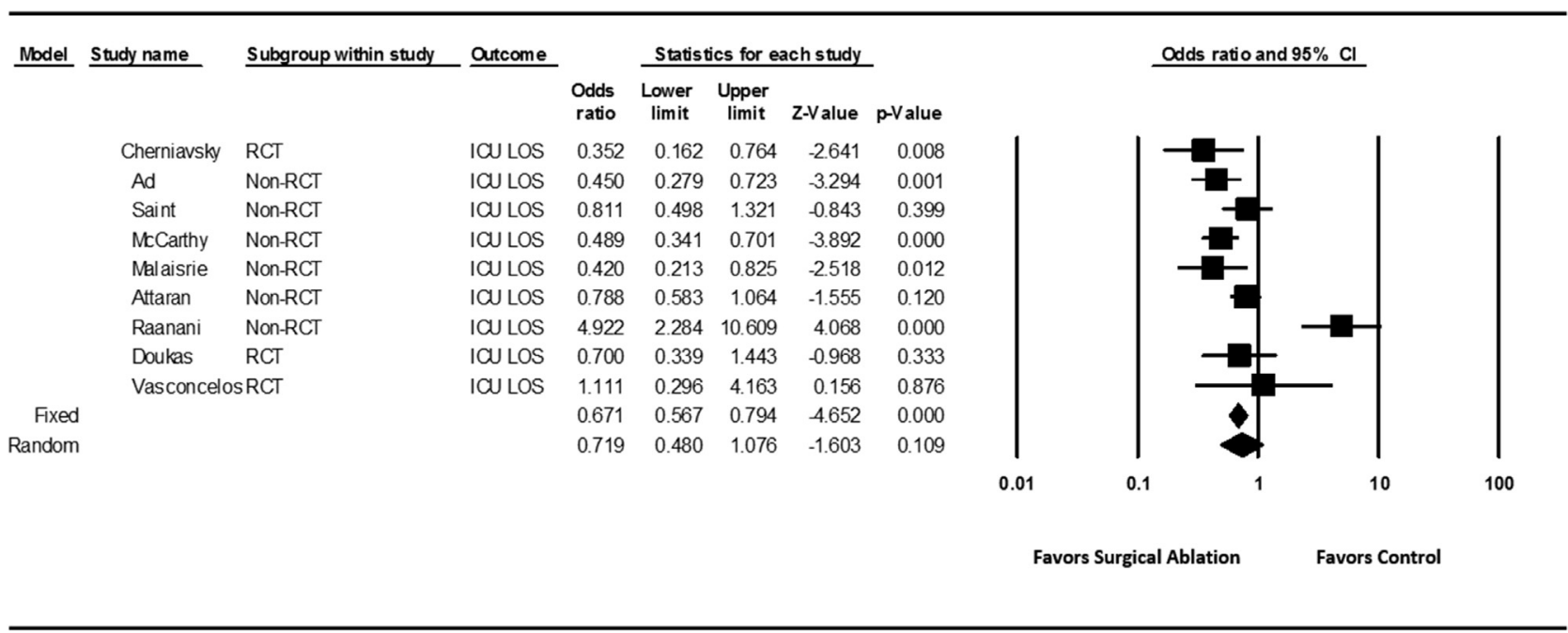

\section{Meta Analysis}

FIGURE 5. Forest plot for length of stay in the ICU in the perioperative time frame ( $<30$ days) with concomitant surgical ablation. $C I$, Confidence interval; $R C T$, randomized controlled trial; $L O S$, length of stay.

$\left(\mathrm{I}^{2}=12.621 \%, \mathrm{Q}=8.011, P=.332\right)$, the level of evidence is fairly strong to indicate that there is a benefit for the perioperative outcome of pneumonia associated with performing a concomitant surgical ablation procedure.

The evidence in this group of studies that met inclusion criteria showed no significant increase or reduction in the incidence of all other perioperative morbidities assessed, which included deep sternal wound infection (Figure 4), length of stay in the ICU (Figure 5), total hospital length of stay (Figure 6), readmissions within 30 days (Figure 7), reoperation for bleeding (Figure 8), renal failure
(Figure 9), and renal failure requiring dialysis (Figure 10). The sample size was highest for reoperation for bleeding $(\mathrm{n}=15)$ and total length of stay $(\mathrm{n}=14)$, and lowest for readmissions within 30 days $(\mathrm{n}=2)$, with all other analyses ranging from sample sizes of 4 to 9 studies. Publication bias was found to be low for pneumonia, deep sternal wound infection, reoperation for bleeding, renal failure, and renal failure requiring dialysis; moderate for ICU length of stay and total length of stay; and undetermined for readmissions within 30 days because of small sample size.

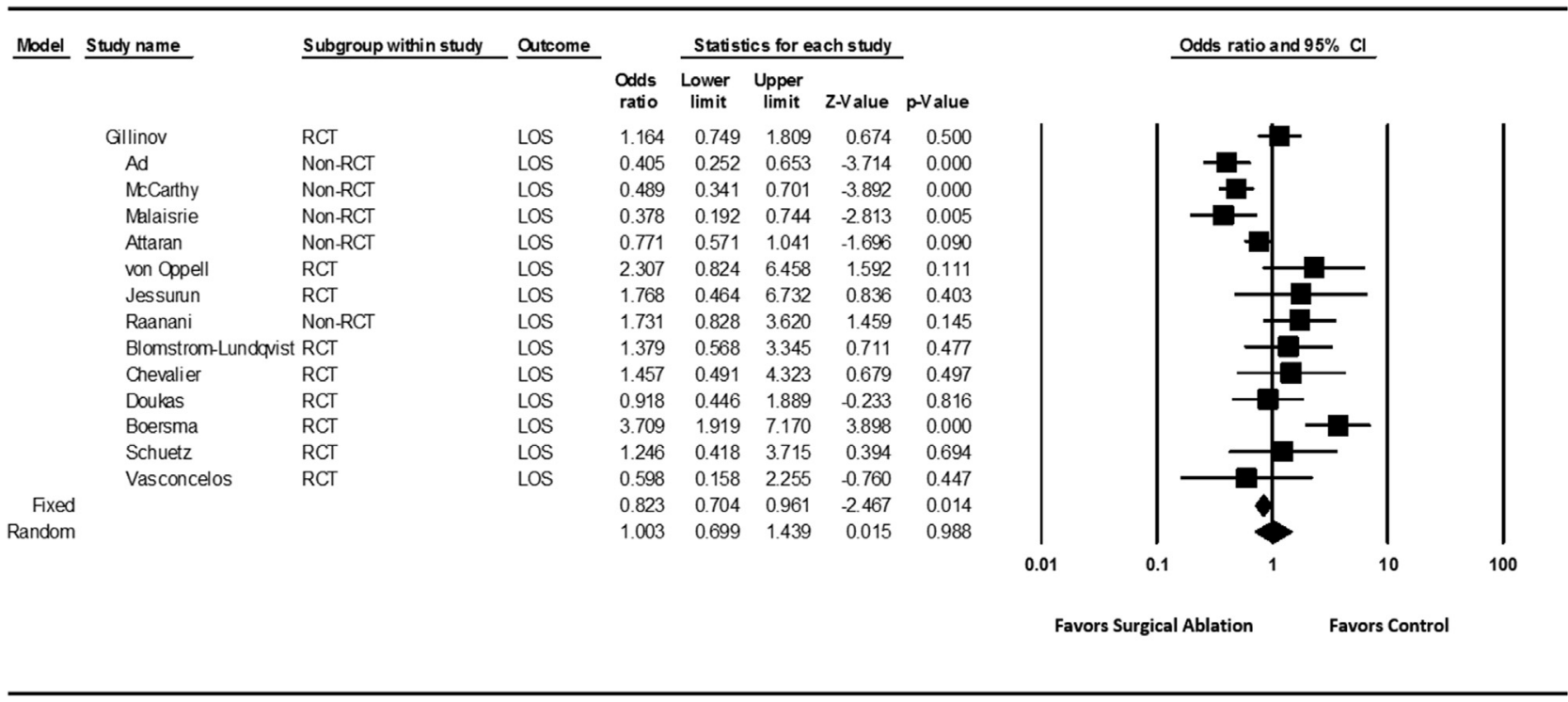

\section{Meta Analysis}

FIGURE 6. Forest plot for total hospital stay in the perioperative time frame $(<30$ days $)$ with concomitant surgical ablation. $C I$, Confidence interval; $R C T$, randomized controlled trial; $L O S$, length of stay. 


\begin{tabular}{|c|c|c|c|c|c|c|c|c|}
\hline \multirow[t]{2}{*}{ Model } & \multirow[t]{2}{*}{ Study name } & \multirow[t]{2}{*}{ Subgroup within study } & \multirow[t]{2}{*}{ Outcome } & \multirow[b]{2}{*}{$\begin{array}{l}\text { Odds } \\
\text { ratio }\end{array}$} & \multicolumn{3}{|c|}{ Statistics for each study } & \multirow[b]{2}{*}{$\mathrm{p}$-Value } \\
\hline & & & & & $\begin{array}{l}\text { Lower } \\
\text { limit }\end{array}$ & $\begin{array}{c}\text { Upper } \\
\text { limit }\end{array}$ & Z-Value & \\
\hline & $\mathrm{Ad}$ & Non-RCT & Readmit $<30$ days & 3.231 & 0.953 & 10.948 & 1.883 & 0.060 \\
\hline & McCarthy & Non-RCT & Readmit $<30$ days & 1.184 & 0.645 & 2.170 & 0.545 & 0.586 \\
\hline Fixed & & & & 1.444 & 0.839 & 2.485 & 1.326 & 0.185 \\
\hline
\end{tabular}

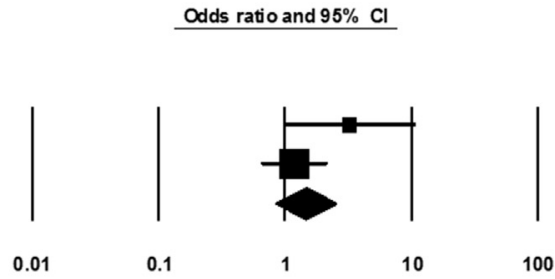

Favors Surgical Ablation

Favors Control

\section{Meta Analysis}

FIGURE 7. Forest plot for readmissions within 30 days with concomitant surgical ablation. $C I$, Confidence interval; RCT, randomized controlled trial.

The analyses of ICU length of stay $\left(\mathrm{I}^{2}=79.118 \%\right.$, $\mathrm{Q}=38.311, P<.001)$ and total hospital length of stay $\left(\mathrm{I}^{2}=76.952 \%, \mathrm{Q}=56.404, P<.001\right)$ were the only 2 with a significant level of heterogeneity present, and therefore the random effects results are reported. The fixed-effects model results indicated a significant reduction in ICU and total length of stay associated with performing a concomitant surgical ablation procedure. It appears that separating the analyses by RCT and non-RCT studies shows a more consistent result in the length of stay outcomes for the RCT study subgroup analyses, whereas more heterogeneity exists within the non-RCT study subgroup analyses. Within the RCT study subgroup analyses, ICU length of stay was reduced with a concomitant surgical ablation procedure (OR, $0.566 ; 95 \%$ CI, 0.346-0.925;
$P=.023)$, whereas total length of stay was increased with a concomitant surgical ablation procedure (OR, 1.452; 95\% CI, 1.115-1.890; $P=.006)$.

Research Question 2A: Does concomitant surgical ablation for $\mathrm{AF}$ reduce the incidence of perioperative stroke/TIA (in-hospital or $<30$ days)?

Recommendation \#2. Addition of a concomitant surgical ablation procedure for $\mathrm{AF}$ does not change the incidence of perioperative stroke/TIA (Class IIa, Level A).

Reasoning. The current literature demonstrates neither increase nor decrease of incidence of perioperative stroke/ TIA. Specifically, the meta-analysis indicates that there is

\begin{tabular}{|c|c|c|c|c|c|c|c|c|}
\hline \multirow[t]{2}{*}{ Model } & \multirow[t]{2}{*}{ Study name } & \multirow[t]{2}{*}{ Subgroup within study } & \multirow[t]{2}{*}{ Outcome } & \multirow[b]{2}{*}{$\begin{array}{l}\text { Odds } \\
\text { ratio }\end{array}$} & \multicolumn{3}{|c|}{ Statistics for each study } & \multirow[b]{2}{*}{ p-Valu } \\
\hline & & & & & $\begin{array}{l}\text { Lower } \\
\text { limit }\end{array}$ & $\begin{array}{c}\text { Upper } \\
\text { limit }\end{array}$ & Z-Value & \\
\hline & $Y 00$ & Non-RCT & Reop for bleeding & 2.386 & 0.637 & 8.934 & 1.291 & 0.1 \\
\hline & $\mathrm{Ad}$ & Non-RCT & Reop for bleeding & 0.734 & 0.185 & 2.911 & -0.441 & 0.6 \\
\hline & Saint & Non-RCT & Reop for bleeding & 0.444 & 0.133 & 1.490 & -1.314 & \\
\hline & McCarthy & Non-RCT & Reop for bleeding & 0.366 & 0.141 & 0.948 & -2.069 & 0.0 \\
\hline & Budera & $\mathrm{RCT}$ & Reop for bleeding & 0.975 & 0.380 & 2.502 & -0.053 & \\
\hline & Kim JB & Non-RCT & Reop for bleeding & 0.784 & 0.384 & 1.601 & -0.668 & \\
\hline & Attaran & Non-RCT & Reop for bleeding & 0.930 & 0.472 & 1.833 & -0.208 & \\
\hline & Raanani & Non-RCT & Reop for bleeding & 14.880 & 0.813 & 272.168 & 1.821 & \\
\hline & Jatene & Non-RCT & Reop for bleeding & 5.462 & 0.212 & 140.565 & 1.024 & \\
\hline & Akpinar & $\mathrm{RCT}$ & Reop for bleeding & 1.031 & 0.062 & 17.200 & 0.021 & \\
\hline & Srivastava & RCT & Reop for bleeding & 0.487 & 0.078 & 3.026 & -0.772 & 0.4 \\
\hline & Albrecht & RCT & Reop for bleeding & 1.557 & 0.061 & 39.945 & 0.267 & \\
\hline & de Lima & $\mathrm{RCT}$ & Reop for bleeding & 0.154 & 0.006 & 4.154 & -1.112 & \\
\hline & Boersma & $\mathrm{RCT}$ & Reop for bleeding & 3.149 & 0.126 & 78.801 & 0.698 & \\
\hline & Vasconcelo & SRCT & Reop for bleeding & 3.000 & 0.113 & 79.914 & 0.656 & 0. \\
\hline Fixed & & & & 0.836 & 0.601 & 1.164 & -1.061 & \\
\hline
\end{tabular}

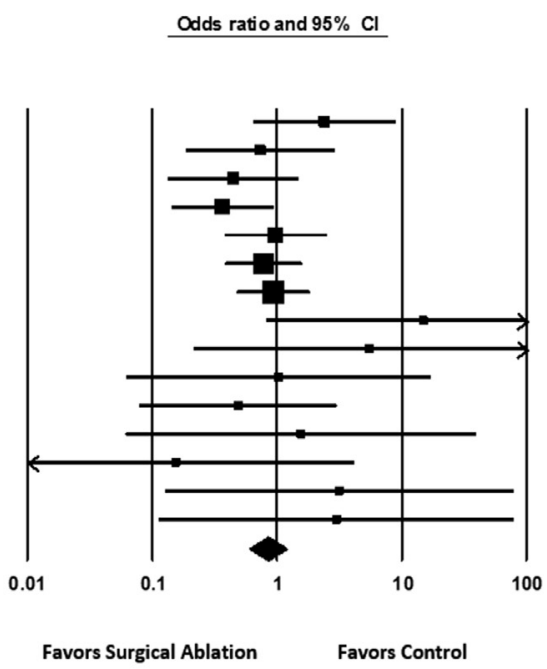

Meta Analysis

FIGURE 8. Forest plot for reoperation for bleeding in the perioperative time frame ( $<30$ days $)$ with concomitant surgical ablation. CI, Confidence interval; $R C T$, randomized controlled trial. 


\begin{tabular}{|c|c|c|c|c|c|c|c|c|}
\hline \multirow[t]{2}{*}{ Model } & \multirow[t]{2}{*}{ Study name } & \multirow[t]{2}{*}{ Subgroup within study } & \multirow[t]{2}{*}{ Outcome } & \multirow[b]{2}{*}{$\begin{array}{l}\text { Odds } \\
\text { ratio }\end{array}$} & \multicolumn{3}{|c|}{ Statistics for each study } & \multirow[b]{2}{*}{$\mathrm{p}$-Value } \\
\hline & & & & & $\begin{array}{c}\text { Lower } \\
\text { limit }\end{array}$ & $\begin{array}{c}\text { Upper } \\
\text { limit }\end{array}$ & Z-Value & \\
\hline & Ad & Non-RCT & RF & 0.543 & 0.154 & 1.907 & -0.953 & 0.34 \\
\hline & Saint & Non-RCT & RF & 1.052 & 0.380 & 2.915 & 0.098 & 0.92 \\
\hline & Attaran & Non-RCT & RF & 0.639 & 0.360 & 1.133 & -1.534 & 0.12 \\
\hline & Raanani & Non-RCT & RF & 5.220 & 0.244 & 111.711 & 1.057 & $0.2 S$ \\
\hline Fixed & & & & 0.725 & 0.458 & 1.147 & -1.374 & 0.1 \\
\hline
\end{tabular}

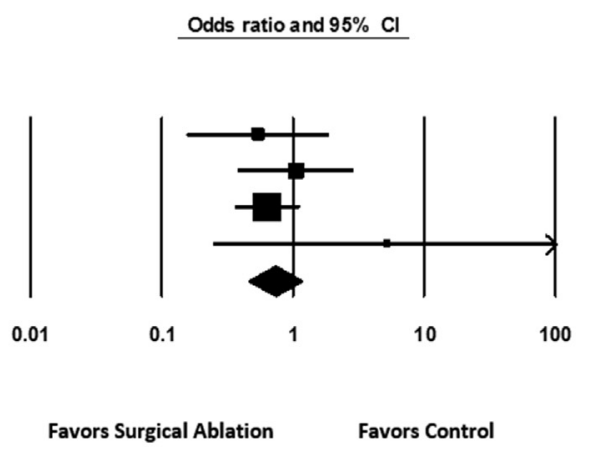

\section{Meta Analysis}

FIGURE 9. Forest plot for renal failure in the perioperative time frame $(<30$ days $)$ with concomitant surgical ablation. $C I$, Confidence interval; $R C T$, randomized controlled trial; $R F$, radiofrequency.

no increase in the incidence of perioperative stroke/TIA for surgical ablation (OR, 0.463; 95\% CI, 0.212-1.011; $P=.053$ ) (Figure 11). In fact, this combined effect appears to indicate that surgical ablation actually decreases the incidence of perioperative stroke/TIA, but the analysis did not reach statistical significance. Publication bias was found to be low for this analysis. With 6 RCT and 6 non-RCT studies included in this analysis, the level of evidence is fairly strong to indicate there is no perioperative safety issue, in regard to stroke/TIA, associated with performing a concomitant surgical ablation procedure.

Research Question 2B. Does concomitant surgical ablation for $\mathrm{AF}$ reduce the incidence of late stroke/TIA?

Recommendation \#3. Overall, addition of a concomitant surgical ablation procedure for AF does not change the incidence of late stroke/TIA, but subgroup analysis of non-RCTs found a significant reduction in late stroke/TIA incidence (Class IIa, Level A for no change in incidence of stroke/TIA for up to 1 year of follow-up after surgery and Level $\mathrm{B}-\mathrm{NR}$ for reduction in incidence of stroke/TIA $>1$ year of follow-up after surgery).

Reasoning. The overall evidence from a meta-analysis conducted to examine the incidence of late stroke/TIA after concomitant surgical ablation indicates that there is no significant decrease (or increase) in the incidence of late stroke/TIA for surgical ablation (OR, 0.505; 95\% CI, 0.211-1.208; $P=.125$ ) (Figure 12). However, further analyses found a significant level of heterogeneity present for the follow-up stroke/TIA analysis $\left(\mathrm{I}^{2}=48.29 \%\right.$, $\mathrm{Q}=19.337, P=.036)$. Therefore, subgroup analyses by

\begin{tabular}{|c|c|c|c|c|c|c|c|c|}
\hline \multirow[t]{2}{*}{ Mbdel } & \multirow[t]{2}{*}{ Study name } & \multirow[t]{2}{*}{ Subgroup within study } & \multirow[t]{2}{*}{ Outcome } & \multirow[b]{2}{*}{$\begin{array}{l}\text { Odds } \\
\text { ratio }\end{array}$} & \multicolumn{3}{|c|}{ Statistics for each study } & \\
\hline & & & & & $\begin{array}{c}\text { Lower } \\
\text { limit }\end{array}$ & $\begin{array}{l}\text { Upper } \\
\text { limit }\end{array}$ & Z-Value & p-Val \\
\hline & Yoo & Non-RCT & RF, dialysis & 3.130 & 0.551 & 17.786 & 1.287 & \\
\hline & $\mathrm{Ad}$ & Non-RCT & RF, dialysis & 0.629 & 0.113 & 3.506 & -0.528 & 0.5 \\
\hline & Budera & RCT & RF, dialysis & 0.213 & 0.023 & 1.938 & -1.373 & 0.1 \\
\hline & Kim JB & Non-RCT & RF, dialysis & 0.953 & 0.287 & 3.160 & -0.079 & \\
\hline & Doukas & RCT & RF, dialysis & 0.457 & 0.107 & 1.942 & -1.062 & \\
\hline Fixed & & & & 0.782 & 0.389 & 1.573 & -0.690 & \\
\hline
\end{tabular}

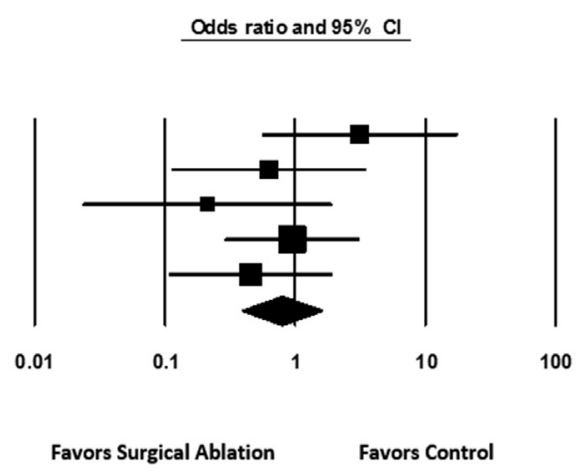

Meta Analysis

FIGURE 10. Forest plot for renal failure requiring dialysis in the perioperative time frame ( $<30$ days $)$ with concomitant surgical ablation. $C I$, Confidence interval; $R C T$, randomized controlled trial; $R F$, radiofrequency. 


\begin{tabular}{|c|c|c|c|c|c|c|c|}
\hline \multirow[t]{2}{*}{ Model } & \multirow[t]{2}{*}{ Studyname } & \multirow[t]{2}{*}{ Time point } & \multirow[b]{2}{*}{$\begin{array}{l}\text { Odds } \\
\text { ratio }\end{array}$} & \multicolumn{3}{|c|}{ Statistics for each study } & \multirow[b]{2}{*}{$p$-Value } \\
\hline & & & & $\begin{array}{l}\text { Lower } \\
\text { limit }\end{array}$ & $\begin{array}{l}\text { Upper } \\
\text { limit }\end{array}$ & Z-Value & \\
\hline & $\mathrm{Ad}, \mathrm{N}$ & Perioperative & 0.155 & 0.014 & 1.738 & -1.512 & 0.131 \\
\hline & Nakajima, H & Perioperative & 0.345 & 0.016 & 7.249 & -0.685 & 0.493 \\
\hline & Raanani, E & Perioperative & 0.326 & 0.013 & 8.217 & -0.680 & 0.496 \\
\hline & Mantovan, R & Perioperative & 0.805 & 0.032 & 20.310 & -0.132 & 0.895 \\
\hline & Johansson, $B$ & Perioperative & 0.487 & 0.042 & 5.601 & -0.578 & 0.564 \\
\hline & Jatene, MB & Perioperative & 0.111 & 0.006 & 2.075 & -1.472 & 0.141 \\
\hline & Doukas, G & Perioperative & 2.000 & 0.175 & 22.815 & 0.558 & 0.57 \\
\hline & Albrecht, A & Perioperative & 0.160 & 0.006 & 4.122 & -1.105 & 0.269 \\
\hline & Blamstram-Lundqvist, C & Perioperative & 3.179 & 0.125 & 80.789 & 0.701 & 0.483 \\
\hline & Jessurun, ER & Perioperative & 0.124 & 0.005 & 3.321 & -1.244 & 0.213 \\
\hline & Budera, $\mathrm{P}$ & Perioperative & 0.430 & 0.077 & 2.397 & -0.963 & 0.336 \\
\hline & Vasconcelos, JT & Perioperative & 3.000 & 0.113 & 79.914 & 0.656 & 0.512 \\
\hline Fixed & & & 0.463 & 0.212 & 1.011 & -1.933 & \\
\hline
\end{tabular}

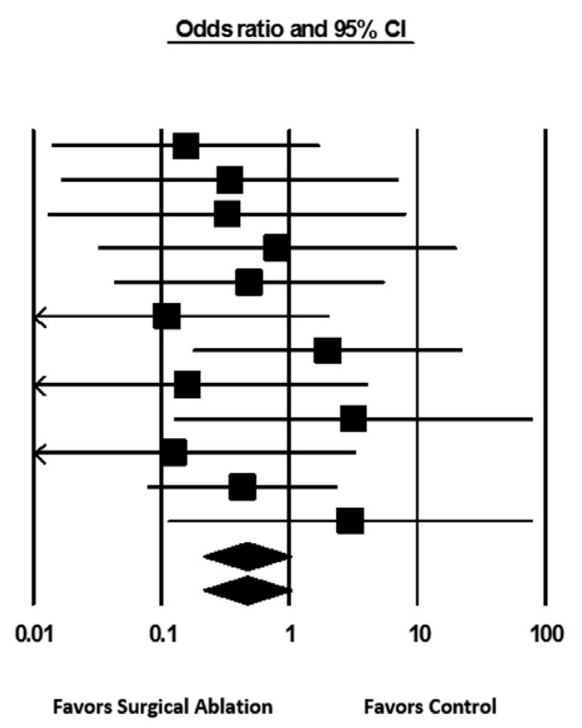

\section{Meta Analysis}

FIGURE 11. Forest plot for incidence of perioperative stroke/TIA (in-hospital or $<30$ days) with concomitant surgical ablation. $C I$, Confidence interval.

duration of follow-up were performed to evaluate this heterogeneity further. This research question was then examined separately for RCT and non-RCT studies because it was noted that all 6 RCT studies included a 12-month follow-up period, whereas the 5 non-RCT studies included varying follow-up time periods, but all were longer than 12 months. The RCT studies showed a consistent pattern with no decrease in follow-up stroke/TIA incidence associated with surgical ablation during the first 12 months after surgery (OR, 1.014; 95\% CI, 0.413-2.492; $P=.976$ ) (Figure 13, A). Conversely, the meta-analysis of non-RCT studies showed a significantly lower incidence of follow-up stroke/TIA for the patients with surgical ablation (OR, 0.269; 95\% CI, 0.078-0.926; $P=.037$ ) (Figure 13, $B$ ). Neither subgroup analysis was found to have a significant level of heterogeneity, but the non-RCT analysis did show

\begin{tabular}{|c|c|c|c|c|c|c|c|}
\hline \multirow[t]{2}{*}{ Model } & \multirow[t]{2}{*}{ Studyname } & \multirow[t]{2}{*}{ Time point } & \multirow[b]{2}{*}{$\begin{array}{l}\text { Odds } \\
\text { ratio }\end{array}$} & \multicolumn{3}{|c|}{ Statistics for each study } & \multirow[b]{2}{*}{ p-Value } \\
\hline & & & & $\begin{array}{c}\text { Lower } \\
\text { limit }\end{array}$ & $\begin{array}{c}\text { Upper } \\
\text { limit }\end{array}$ & Z-Value & \\
\hline & Nakajima, $\mathrm{H}$ & Follow-up & 0.124 & 0.029 & 0.535 & -2.800 & 0.005 \\
\hline & Raanani, E & Follow-up & 0.081 & 0.004 & 1.515 & -1.682 & 0.093 \\
\hline & Johansson, B & Follow-up & 1.000 & 0.189 & 5.289 & 0.000 & 1.000 \\
\hline & Doukas, G & Follow-up & 0.188 & 0.009 & 4.018 & -1.070 & 0.285 \\
\hline & Blamstrom-Lundq vist, C & Follow-up & 2.200 & 0.376 & 12889 & 0.874 & 0.382 \\
\hline & Alppinar, B & Follow-up & 0.194 & 0.009 & 4.199 & -1.045 & 0.296 \\
\hline & Bando, K & Follow-up & 0.091 & 0.021 & 0.392 & -3.220 & 0.001 \\
\hline & Wang, J & Follow-up & 2.025 & 0.180 & 22.770 & 0.571 & 0.568 \\
\hline & Budera, P & Follow-up & 0.611 & 0.133 & 2.803 & -0.634 & 0.526 \\
\hline & Vasconcelos, JT & Follow-up & 3.000 & 0.113 & 79.914 & 0.656 & 0.512 \\
\hline & Chevalier, P & Follow-up & 3.500 & 0.334 & 36.667 & 1.045 & 0.296 \\
\hline Random & & & 0.505 & 0.211 & 1.208 & -1.535 & \\
\hline
\end{tabular}

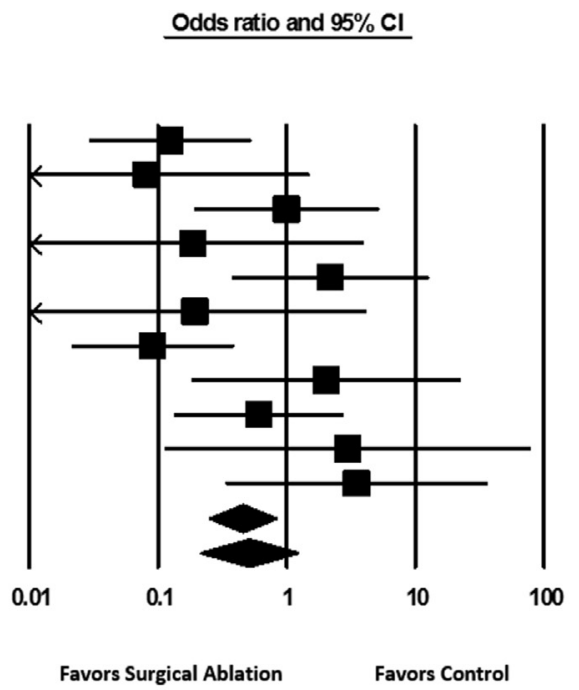

Meta Analysis

FIGURE 12. Forest plot for incidence of late stroke/TIA with concomitant surgical ablation. $C I$, Confidence interval. 


\begin{tabular}{|c|c|c|c|c|c|c|c|c|}
\hline \multirow[t]{2}{*}{ Model } & \multirow[t]{2}{*}{ Study name } & \multirow[t]{2}{*}{ Comparison } & \multirow[t]{2}{*}{ Time point } & \multirow[b]{2}{*}{$\begin{array}{l}\text { Odds } \\
\text { ratio }\end{array}$} & \multicolumn{3}{|c|}{ Statis tics for each study } & \multirow[b]{2}{*}{ p-Value } \\
\hline & & & & & $\begin{array}{l}\text { Lower } \\
\text { limit }\end{array}$ & $\begin{array}{c}\text { Upper } \\
\text { limit }\end{array}$ & $Z$ ZValue & \\
\hline & Doukas, G & RCT & Follow-up & 0.188 & 0.009 & 4.018 & -1.070 & \\
\hline & Bloms trom-L undquis $t, C$ & RCT & Follow-up & 2.200 & 0.376 & 12.889 & 0.874 & 0.3 \\
\hline & Akpinar, B & $\mathrm{RCT}$ & Follow-up & 0.194 & 0.009 & 4.199 & -1.045 & 0.2 \\
\hline & Buders, $P$ & $\mathrm{RCT}$ & Follow-up & 0.811 & 0.133 & 2.803 & -0.834 & 0.5 \\
\hline & Vas concelos. JT & RCT & Follow-up & 3.000 & 0.113 & 79.914 & 0.658 & \\
\hline & Chevalier, $\mathrm{P}$ & $\mathrm{RCT}$ & Follow-up & 3.500 & 0.334 & 36.687 & 1.045 & \\
\hline Fixed & & & & 1.014 & 0.413 & 2.492 & 0.030 & \\
\hline
\end{tabular}

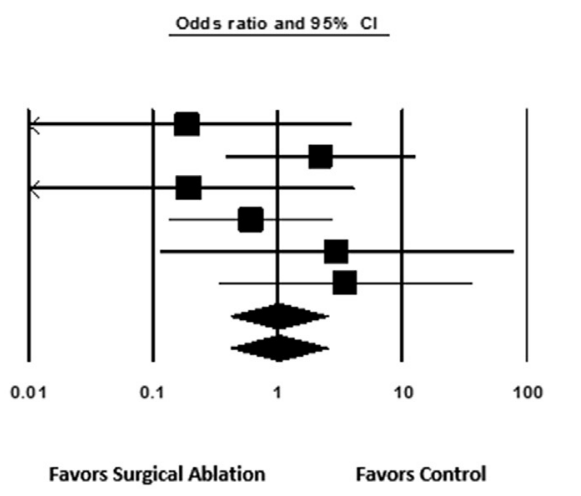

Meta Analysis

A

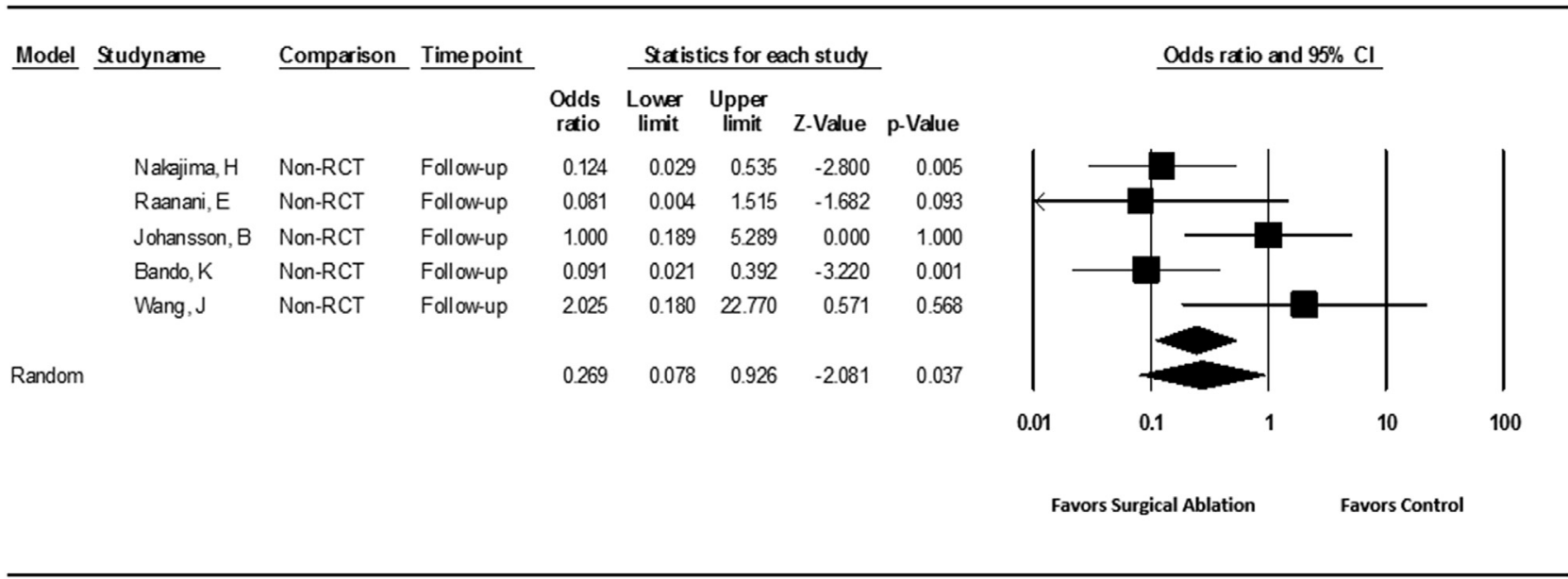

\section{Meta Analysis}

\section{B}

FIGURE 13. A, Forest plot for incidence of late stroke/TIA with concomitant surgical ablation in randomized controlled studies. B, Forest plot for incidence of late stroke/TIA with concomitant surgical ablation in nonrandomized controlled studies. $C I$, Confidence interval; RCT, randomized controlled trial.

more heterogeneity than the RCT analysis, likely because of the varying follow-up time still present within the non-RCT analysis. Publication bias was found to be moderate for this outcome.

Research Question 3. Does concomitant surgical ablation for AF improve HRQL and AF-related symptoms?

Recommendation \#4. A surgical procedure that includes concomitant surgical ablation for $\mathrm{AF}$ does improve HRQL. Addition of concomitant surgical ablation for AF does improve AF-related symptoms, and this improvement is greater than in patients without surgical ablation for AF (Class
IIa, Level B-R for HRQL, and Level C-LD for AF-related symptoms).

Reasoning. Overall, the current literature demonstrates that patients following surgical ablation have significant improvements in HRQL postsurgery. For AF-specific symptoms and AF-reported symptom frequency and severity after surgery, patients with surgical ablation demonstrated more positive improvements than patients without surgical ablation.

Specifically, the evidence from the systematic review focusing on HRQL indicates that when measured before and after surgery, cardiac surgery with surgical ablation can improve HRQL, but these changes are similar for 
patients undergoing cardiac surgery without surgical ablation. When measured only after surgery, patients with and without surgical ablation can expect to report similar levels of HRQL.

All 4 RCT studies used a version of the Medical Outcomes Study Short Form Health Survey (SF-12 or SF-36) to measure HRQL. Two studies included preoperative and postoperative HRQL measures. von Oppell and colleagues ${ }^{24}$ found that 5 of the 8 SF-36 subscale scores improved significantly between preoperative and postoperative measures, but improvement was similar between treatment groups. Likewise, Jessurun and colleagues $^{33}$ found significant improvement from preoperative to postoperative measures on 2 of the 8 SF-36 subscales in patients with surgical ablation, but the group without surgical ablation also showed improvement in 2 of the 8 SF-36 subscales. The other 2 studies included postoperative HRQL measures only. Gillinov and colleagues found no significant difference in SF-12 mental composite score (MCS) or physical composite score (PCS) at 1 year after surgery between patients with and without surgical ablation. ${ }^{10}$ The study by Forlani and colleagues ${ }^{47}$ found that patients who underwent surgical ablation were more likely to be in the "good quality of life" group than the "poor quality of life" group after surgery, but there were no analyses of the raw SF-36 scores by treatment group.

Both nonrandomized controlled studies used matching techniques to select the control groups. The results from these studies were comparable to those of the RCT studies. In the study by Ad and colleagues, improvement in SF-12 PCS and MCS from preoperative to 6 months postoperative was similar for patients with and without surgical ablation. ${ }^{45}$ In addition, the study by Johansson and colleagues $^{39}$ found no significant difference on any SF-36 scores between patients with and without surgical ablation when measured at long-term follow-up after surgery.

In the 3 studies that did not include a control group, the results showed a consistent message as the other controlled studies. Ad and colleagues found significant improvement from preoperatively to 1 year postoperatively in SF-12 PCS and MCS, ${ }^{43}$ whereas Bakker and colleagues ${ }^{44}$ found no significant difference between their study sample and the general population normal values in any of the SF-36 subscales at follow-up after surgery. The study by Grubitzsch and colleagues ${ }^{46}$ examined HRQL differently using the Minnesota Living with Heart Failure Questionnaire and comparisons by congestive heart failure and rhythm status after surgery. Patients with severe congestive heart failure who regained sinus rhythm after surgery had lower Minnesota Living with Heart Failure total score and Minnesota Living with Heart Failure physical component score compared with patients who did not regain sinus rhythm, but no effect of rhythm status was found for patients with moderate congestive heart failure.

In contrast to the HRQL results, the evidence from this systematic review indicates that cardiac surgery with surgical ablation is associated with improvement in reported AF-specific symptoms and reduced AF-related symptom frequency and severity after surgery compared with patients without surgical ablation. Four studies examined the outcome of symptom status, mostly those specific to AF. The RCT by Gillinov and colleagues found that patients receiving surgical ablation reported a significantly lower frequency of AF at 1 year after surgery compared with patients without surgical ablation. ${ }^{10}$ In a nonrandomized controlled study, Johansson and colleagues $^{39}$ found that severity but not frequency of AF-specific symptoms was lower in the surgical ablation group compared with the control group when measured at long-term follow-up. Likewise, in the study by $\mathrm{Ad}$ and colleagues without a control group, the frequency and severity of AF-specific symptoms decreased significantly from preoperatively to 6 months postoperatively. ${ }^{43}$ By using a different measure of symptoms, the RCT by Jessurun and colleagues $^{33}$ found that patient-reported change in health was significantly improved from preoperatively to 3 months postoperatively in patients with and without surgical ablation, but only the patients with surgical ablation had further significant improvement from 3 to 12 months after surgery.
Research Question 4A: Does concomitant surgical ablation for $\mathrm{AF}$ improve operative survival $(<30$ days $)$ ?

Recommendation \#5. Addition of concomitant surgical ablation for AF does improve 30-day operative mortality (Class I, Level A)

Reasoning. The evidence indicates that surgical ablation is associated with improved survival in the perioperative time frame (OR, 0.643; 95\% CI, 0.464-0.890; $P=.008$ ) (Figure 14). In fact, the surgical ablation group had $36 \%$ reduced odds for perioperative mortality. With $10 \mathrm{RCT}$ and 14 non-RCT studies included in this analysis, no heterogeneity identified $\left(\mathrm{I}^{2}=0 \%, \mathrm{Q}=18.135\right.$, $P=.750$ ), and low publication bias, the level of evidence is fairly strong to indicate that there is a benefit for shortterm survival associated with performing a concomitant surgical ablation procedure.

Research Question 4B: Does concomitant surgical ablation for AF improve long-term survival (>30 days)?

Recommendation \#6. Overall, addition of a concomitant surgical ablation procedure for $\mathrm{AF}$ 


\begin{tabular}{|c|c|c|c|c|c|c|c|c|}
\hline \multirow[t]{2}{*}{ Model } & \multirow[t]{2}{*}{ Study name } & \multirow[t]{2}{*}{ Comparison } & \multirow[t]{2}{*}{ Time point } & \multirow[b]{2}{*}{$\begin{array}{l}\text { Odds } \\
\text { ratio }\end{array}$} & \multicolumn{3}{|c|}{ Statistics for each study } & \multirow[b]{2}{*}{$\mathrm{p}$-Value } \\
\hline & & & & & $\begin{array}{l}\text { Lower } \\
\text { limit }\end{array}$ & $\begin{array}{c}\text { Upper } \\
\text { limit }\end{array}$ & Z-V alue & \\
\hline & Yoo & Non-RCT & Operative & 0.483 & 0.049 & 4.780 & -0.622 & 0.534 \\
\hline & Ad & Non-RCT & Operative & 0.303 & 0.085 & 1.077 & -1.845 & 0.065 \\
\hline & Saint & Non-RCT & Operative & 0.618 & 0.144 & 2.653 & -0.648 & 0.517 \\
\hline & Kim HJ & Non-RCT & Operative & 0.971 & 0.404 & 2.331 & -0.066 & 0.947 \\
\hline & McCarthy & Non-RCT & Operative & 0.288 & 0.117 & 0.709 & -2.710 & 0.007 \\
\hline & Budera & $\mathrm{RCT}$ & Operative & 0.869 & 0.331 & 2.281 & -0.285 & 0.776 \\
\hline & Malaisrie & Non-RCT & Operative & 0.350 & 0.056 & 2.182 & -1.124 & 0.261 \\
\hline & KimJB & Non-RCT & Operative & 2.003 & 0.385 & 10.412 & 0.826 & 0.409 \\
\hline & Attaran & Non-RCT & Operative & 0.364 & 0.146 & 0.908 & -2.168 & 0.030 \\
\hline & Louagie & Non-RCT & Operative & 0.571 & 0.109 & 2.986 & -0.663 & 0.507 \\
\hline & Abreu Filho & $\mathrm{RCT}$ & Operative & 2.060 & 0.081 & 52.392 & 0.438 & 0.662 \\
\hline & Knaut & Non-RCT & Operative & 0.171 & 0.020 & 1.489 & -1.600 & 0.110 \\
\hline & Nakajima & Non-RCT & Operative & 5.273 & 0.213 & 130.519 & 1.016 & 0.310 \\
\hline & Chen & Non-RCT & Operative & 0.698 & 0.149 & 3.264 & -0.456 & 0.648 \\
\hline & Raanani & Non-RCT & Operative & 2.044 & 0.179 & 23.348 & 0.576 & 0.565 \\
\hline & Jatene & Non-RCT & Operative & 0.868 & 0.074 & 10.225 & -0.112 & 0.911 \\
\hline & Blomstrom-Lundqvist & $\mathrm{RCT}$ & Operative & 3.179 & 0.125 & 80.789 & 0.701 & 0.483 \\
\hline & Doukas & RCT & Operative & 0.717 & 0.152 & 3.390 & -0.419 & 0.675 \\
\hline & Alpinar & RCT & Operative & 1.031 & 0.062 & 17.200 & 0.021 & 0.983 \\
\hline & Srivastava & RCT & Operative & 3.129 & 0.165 & 59.393 & 0.759 & 0.448 \\
\hline & Albrecht & RCT & Operative & 2.662 & 0.122 & 58.119 & 0.622 & 0.534 \\
\hline & de Lima & RCT & Operative & 1.615 & 0.060 & 43.247 & 0.286 & 0.775 \\
\hline & Schuetz & RCT & Operative & 0.783 & 0.046 & 13.390 & -0.169 & 0.866 \\
\hline & Vasconcelos & RCT & Operative & 3.000 & 0.113 & 79.914 & 0.656 & 0.512 \\
\hline Fixed & & & & 0.643 & 0.464 & 0.890 & -2.664 & 0.008 \\
\hline
\end{tabular}

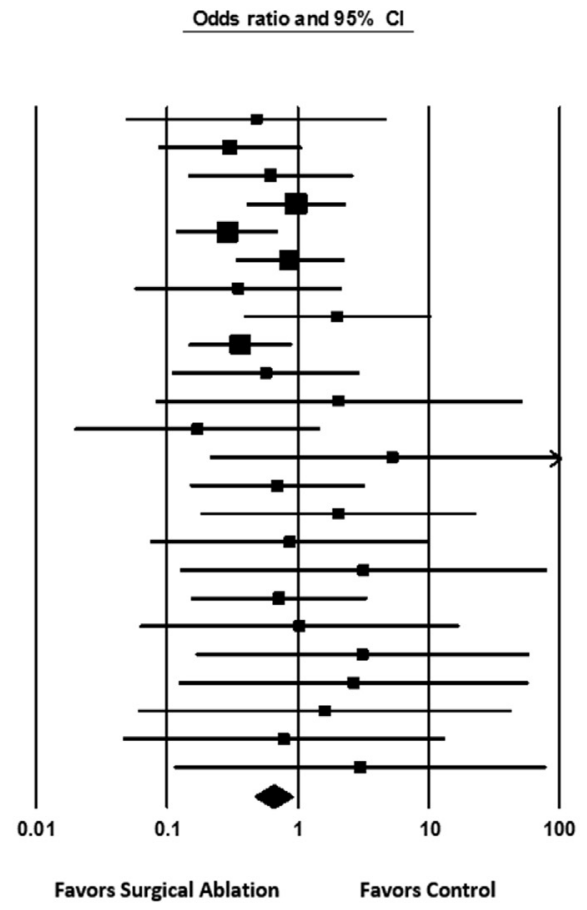

Meta Analysis

FIGURE 14. Forest plot for improved survival in the perioperative time frame ( $<30$ days) with concomitant surgical ablation. $C I$, Confidence interval; $R C T$, randomized controlled trial.

improves long-term survival (Class IIa, Level A for no change in survival up to 1 year after surgery and Level B-NR for improvement in long-term survival of $>1$ year after surgery).

Reasoning. The overall evidence indicates that there is a significant improvement in long-term survival in those with surgical ablation (OR, 0.486; 95\% CI, 0.355-0.665; $P<.001$ ) (Figure 15). However, further analyses found a significant level of heterogeneity present for the long-term survival analysis $\left(\mathrm{I}^{2}=40.41 \%, \mathrm{Q}=45.306, P=.015\right)$. Therefore, subgroup analyses by study design were performed to evaluate this heterogeneity further. Research Question 4B was examined separately for RCT and non-RCT studies because it was noted that all except 3 of the 15 RCT studies included a 12-month follow-up period, whereas the 13 non-RCT studies included varying follow-up time periods, but all include more than 12 months of follow-up. The RCT studies showed a consistent pattern with no significant improvement in long-term survival associated with surgical ablation during the first 12 months after surgery (OR, $0.910 ; 95 \% \mathrm{CI}, 0.588-1.410 ; P=.673$ ) (Figure 16, A). Conversely, the meta-analysis of non-RCT studies showed a significant improvement in long-term survival with concomitant surgical ablation (OR, 0.360; 95\% CI, 0.248-0.522; $P<.001$ ) (Figure 16, B). The RCT analysis did not have significant heterogeneity $\left(\mathrm{I}^{2}=0 \%\right.$, $P=.885$ ), but the non-RCT analysis did identify significant heterogeneity $\left(\mathrm{I}^{2}=50.91 \%, P=.018\right)$, likely due to the varying follow-up times still present within the non-RCT analysis. Publication bias was found to be moderate for this outcome.

\section{AIM 2. Indications for Surgical Ablation Using Hybrid Approaches}

Research Question 5: What are the indications for a hybrid ablation or stand-alone off-pump epicardial ablation in patients with AF?

Recommendation \#7. Overall, hybrid procedures have shown promising results compared with percutaneous catheter ablation in a subgroup of symptomatic patients with $\mathrm{AF}$ in whom medical treatment and percutaneous catheter ablation have failed (Class IIb, Level B-NR).

Recommendation \#8. Overall, minimally invasive approaches to isolate the pulmonary veins bilaterally have shown promising results compared with percutaneous catheter ablation in a subgroup of symptomatic patients with paroxysmal $\mathrm{AF}$ and a small LA in whom medical treatment and 


\begin{tabular}{|c|c|c|c|c|c|c|c|c|}
\hline \multirow[t]{2}{*}{ Mbdel } & \multirow[t]{2}{*}{ Study name } & \multirow[t]{2}{*}{ Comparison } & \multirow[t]{2}{*}{ Time point } & \multirow[b]{2}{*}{$\begin{array}{l}\text { Odds } \\
\text { ratio }\end{array}$} & \multicolumn{3}{|c|}{ Statistics for each study } & \multirow[b]{2}{*}{$\mathrm{p}$-Value } \\
\hline & & & & & $\begin{array}{l}\text { Lower } \\
\text { limit }\end{array}$ & $\begin{array}{l}\text { Upper } \\
\text { limit }\end{array}$ & Z-Value & \\
\hline & Gillinov & RCT & Follow-up & 0.765 & 0.306 & 1.914 & -0.572 & 0.568 \\
\hline & Wang & $\mathrm{RCT}$ & Follow-up & 1.516 & 0.061 & 37.696 & 0.254 & 0.800 \\
\hline & Yoo & Non-RCT & Follow-up & 0.457 & 0.166 & 1.256 & -1.518 & 0.129 \\
\hline & Ad & Non-RCT & Follow-up & 0.428 & 0.175 & 1.044 & -1.865 & 0.06 \\
\hline & $\mathrm{KIm} \mathrm{HJ}$ & Non-RCT & Follow-up & 0.298 & 0.192 & 0.464 & -5.369 & 0.00 \\
\hline & Budera & $\mathrm{RCT}$ & Follow-up & 0.919 & 0.439 & 1.924 & -0.223 & 0.823 \\
\hline & Malaisrie & Non-RCT & Follow-up & 0.205 & 0.059 & 0.710 & -2.499 & 0.012 \\
\hline & Arak & Non-RCT & Follow-up & 1.190 & 0.519 & 2731 & 0.412 & 0.681 \\
\hline & Km JB & Non-RCT & Follow-up & 0.634 & 0.362 & 1.108 & -1.601 & 0.109 \\
\hline & Attaran & Non-RCT & Follow-up & 0.315 & 0.172 & 0.576 & -3.750 & 0.000 \\
\hline & von Oppell & $\mathrm{RCT}$ & Follow-up & 0.192 & 0.009 & 4.210 & -1.048 & 0.295 \\
\hline & Louagie & Non-RCT & Follow-up & 0.120 & 0.033 & 0.430 & -3.256 & 0.001 \\
\hline & Stulak & Non-RCT & Follow-up & 0.207 & 0.010 & 4.491 & -1.004 & 0.316 \\
\hline & Abreu Filho & RCT & Follow-up & 0.667 & 0.088 & 5.035 & -0.393 & 0.69 \\
\hline & Knaut & Non-RCT & Follow-up & 0.309 & 0.135 & 0.708 & -2.774 & 0.00 \\
\hline & Bando & Non-RCT & Follow-up & 0.139 & 0.053 & 0.364 & -4.026 & 0.000 \\
\hline & Deneke & $\mathrm{RCT}$ & Follow-up & 5.091 & 0.496 & 52.285 & 1.369 & 0.171 \\
\hline & Raanani & Non-RCT & Follow-up & 0.068 & 0.004 & 1.254 & -1.808 & 0.071 \\
\hline & Jatene & Non-RCT & Follow-up & 1.833 & 0.238 & 14.133 & 0.582 & 0.561 \\
\hline & Blomstrom-Lundqvist & RCT & Follow-up & 3.179 & 0.125 & 80.789 & 0.701 & 0.483 \\
\hline & Chevalier & RCT & Follow-up & 3.293 & 0.127 & 85.437 & 0.717 & 0.473 \\
\hline & Knaut & RCT & Follow-up & 2.857 & 0.274 & 29.796 & 0.878 & 0.380 \\
\hline & Alpinar & RCT & Follow-up & 0.500 & 0.043 & 5.803 & -0.554 & 0.57 \\
\hline & Srivastava & RCT & Follow-up & 1.177 & 0.234 & 5.911 & 0.198 & 0.843 \\
\hline & Van Breugel & RCT & Follow-up & 0.394 & 0.074 & 2.106 & -1.090 & 0.276 \\
\hline & Albrecht & RCT & Follow-up & 2.662 & 0.122 & 58.119 & 0.622 & 0.53 \\
\hline & Boersma & RCT & Follow-up & 0.339 & 0.014 & 8.478 & -0.659 & 0.51 \\
\hline & Vasconcelos & RCT & Follow-up & 0.287 & 0.011 & 7.704 & -0.743 & \\
\hline Random & & & & 0.486 & 0.355 & 0.665 & -4.501 & 0.00 \\
\hline
\end{tabular}

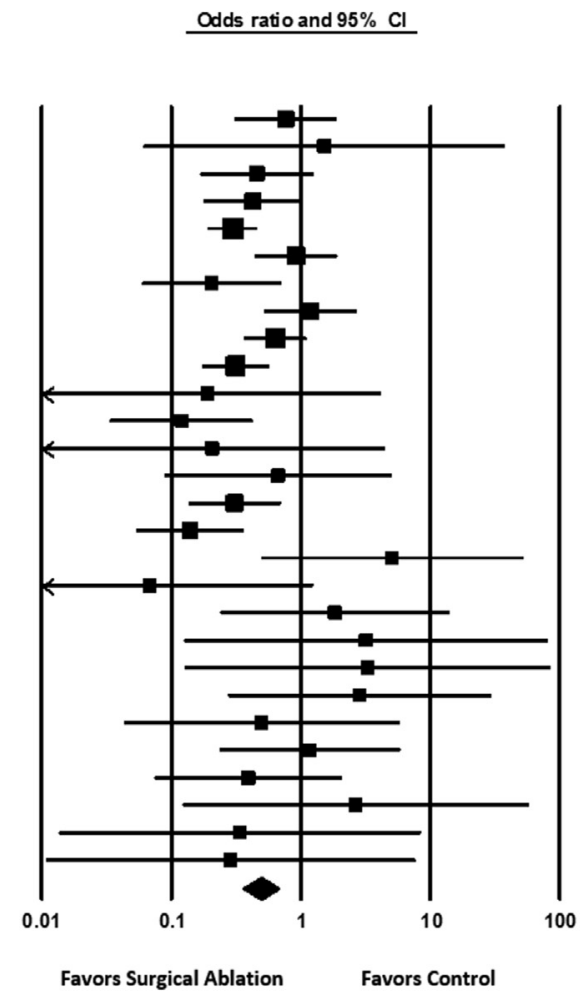

\section{Meta Analysis}

FIGURE 15. Forest plot for improved long-term survival with concomitant surgical ablation. $C I$, Confidence interval; $R C T$, randomized controlled trial.

percutaneous catheter ablation have failed (Class IIa, Level B-R).

Reasoning. The improvement of ablation technology makes surgical approaches in patients with stand-alone AF less invasive. The hybrid AF surgical ablation procedure is defined in the 2012 Heart Rhythm Society/European Heart Rhythm Association/European Cardiac Arrhythmia Society Expert Consensus Statement on Catheter and Surgical Ablation of Atrial Fibrillation, as a joint AF ablation procedure that is a part of a single "joint" procedure or performed as 2 preplanned separate ablation procedures separated by no more than 6 months of time. ${ }^{64}$ Hybrid ablation procedures consist of epicardial surgical ablation combined with percutaneous endocardial ablation. This collaborative effort encompasses partnerships between electrophysiologists and cardiac surgeons in patient selection and treatment. The different hybrid ablation approaches provide an innovative solution for the treatment of AF that can be effective in experienced hands using refined techniques and energy source applications. However, the application of these technologies must be evaluated in the context of safety and the efficacy of alternative methods of surgical ablation, such as the Cox-Maze procedure. A recent thorough meta-analysis compared Cox-Maze and hybrid procedures to find that overall 1-year freedom from AF off antiarrhythmic drugs (AADs) was $87 \%$ versus $71 \%$, respectively, but the complication rates were higher with hybrid procedures. ${ }^{65}$

On the basis of current experience, the hybrid approach with the most effective outcomes and safety profile appears to be bilateral pulmonary vein isolation (PVI) procedures performed surgically with LAA management combined with different endocardial ablation protocols.

Hybrid approaches based on the collaboration of the electrophysiologist and cardiac surgeon could expand the indications for more effective stand-alone interventions for $\mathrm{AF}$ in the future.

With current surgical ablation tools designed for beating heart $\mathrm{AF}$ ablation, technical difficulties are still a potential concern, especially with respect to transmurality of the lesion lines. To better understand the quality of the lesions that are created and the impact of the lesion set, a hybrid approach was designed. The principles of these approaches are based on the understanding that it is possible to apply 


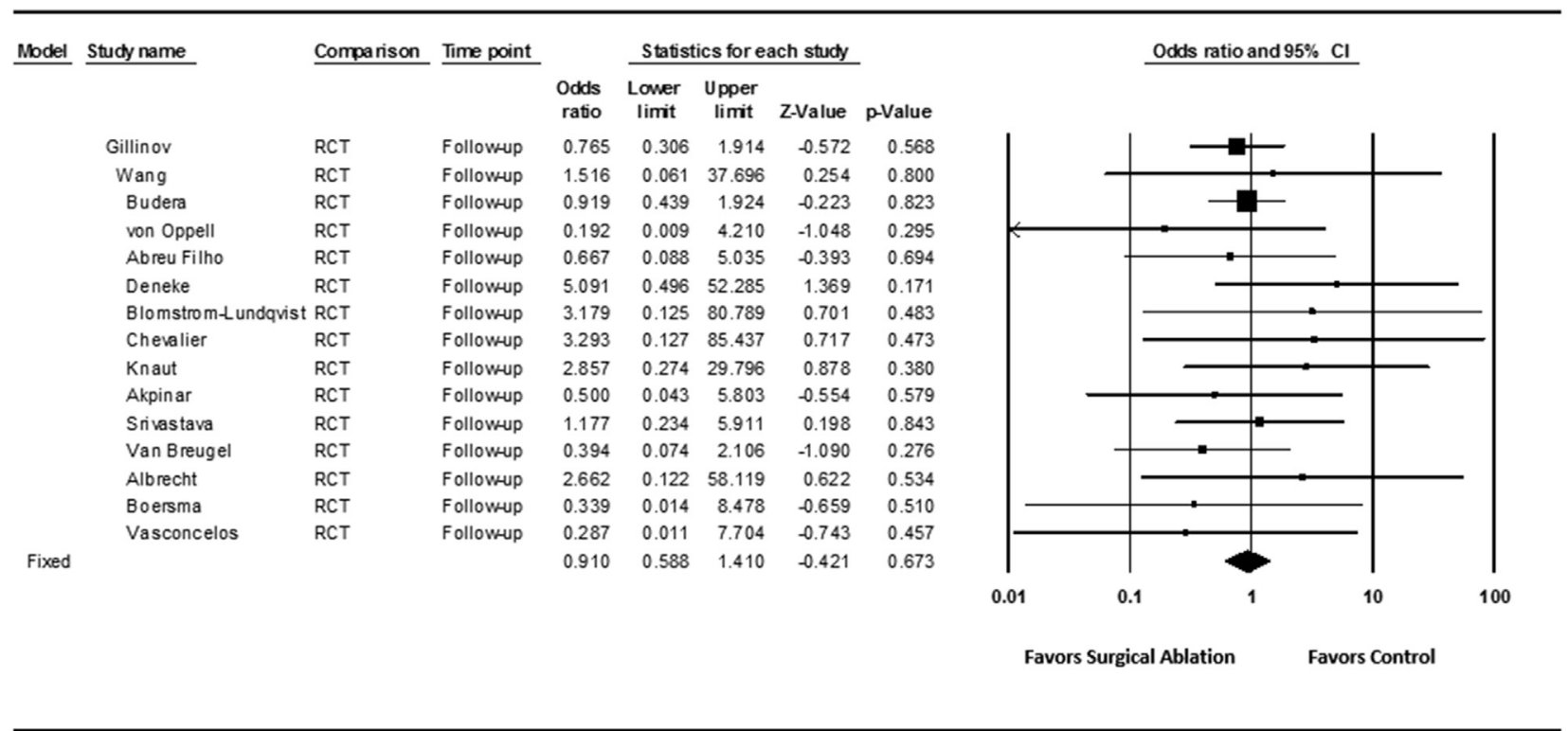

\section{Meta Analysis}

A

\begin{tabular}{|c|c|c|c|c|c|c|c|c|}
\hline \multirow{2}{*}{\multicolumn{2}{|c|}{ Studyname }} & \multirow[t]{2}{*}{ Comparison } & \multirow[t]{2}{*}{ Time point } & \multirow[b]{2}{*}{$\begin{array}{l}\text { Odds } \\
\text { ratio }\end{array}$} & \multicolumn{3}{|c|}{ Statistics for each study } & \multirow[b]{2}{*}{ p-Value } \\
\hline & & & & & $\begin{array}{l}\text { Lower } \\
\text { limit }\end{array}$ & $\begin{array}{l}\text { Upper } \\
\text { limit }\end{array}$ & Z-Value & \\
\hline & Yoo & Non-RCT & Follow-up & 0.457 & 0.166 & 1.256 & -1.518 & 0.129 \\
\hline & $\mathrm{Ad}$ & Non-RCT & Follow-up & 0.428 & 0.175 & 1.044 & -1.865 & 0.062 \\
\hline & $\mathrm{KimHJ}$ & Non-RCT & Follow-up & 0.298 & 0.192 & 0.464 & -5.369 & 0.000 \\
\hline & Malaisrie & Non-RCT & Follow-up & 0.205 & 0.059 & 0.710 & -2.499 & 0.012 \\
\hline & Araki & Non-RCT & Follow-up & 1.190 & 0.519 & 2.731 & 0.412 & 0.681 \\
\hline & $\mathrm{KmJB}$ & Non-RCT & Follow-up & 0.634 & 0.362 & 1.108 & -1.601 & 0.109 \\
\hline & Attar an & Non-RCT & Follow-up & 0.315 & 0.172 & 0.576 & -3.750 & 0.000 \\
\hline & Louagie & Non-RCT & Follow-up & 0.120 & 0.033 & 0.430 & -3.256 & 0.00 \\
\hline & Stulak & Non-RCT & Follow-up & 0.207 & 0.010 & 4.491 & -1.004 & 0.31 \\
\hline & Knaut & Non-RCT & Follow-up & 0.309 & 0.135 & 0.708 & -2.774 & 0.00 \\
\hline & Bando & Non-RCT & Follow-up & 0.139 & 0.053 & 0.364 & -4.026 & 0.00 \\
\hline & Raanani & Non-RCT & Follow-up & 0.068 & 0.004 & 1.254 & -1.808 & 0.07 \\
\hline & Jatene & Non-RCT & Follow-up & 1.833 & 0.238 & 14.133 & 0.582 & 0.5 \\
\hline Randor & & & & 0.360 & 0.248 & 0.522 & -5.401 & 0.000 \\
\hline
\end{tabular}

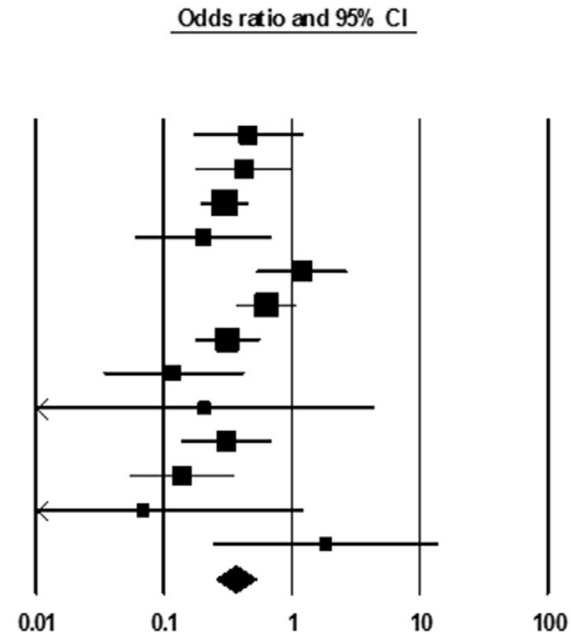

Favors Surgical Ablation Favors Control

\section{Meta Analysis}

B

FIGURE 16. A, Forest plot for long-term survival with concomitant surgical ablation in randomized controlled studies. B, Forest plot for long-term survival with concomitant surgical ablation in nonrandomized controlled studies. $C I$, Confidence interval; $R C T$, randomized controlled trial.

mapping techniques from electrophysiologists to surgical epicardial ablation techniques when performed on the beating heart. The add-on approach can potentially improve the quality of the lesion line and lesion set if necessary. In reality, hybrid procedures often are being performed in a single-stage procedure. ${ }^{66}$ Currently, there is not enough evidence to distinguish between the 1- and 2-stage approach because of the lack of direct comparison and the significant variability in the procedure with regard to lesion set, energy sources, and procedural end points. 
Different hybrid surgical ablation lesions sets are applied, usually in a manner less than the full Cox-Maze IV lesion set. They are performed epicardially via minimally invasive nonsternotomy approaches without cardiopulmonary bypass, followed by catheter-based endocardial mapping, and if necessary additional ablation. Within this category of surgical ablation therapy, there are 3 general categories of innovative procedures currently being performed:

I. Bilateral PVI procedures inclusive of left atrial appendage (LAA) management. This includes a bilateral thoracoscopic or thoracotomy approach to perform isolated right and left antral PVI pairs with or without additional linear lesions on the left and right atrium. An alternative approach is to perform a posterior PVI encircling box lesion.

II. Unilateral thoracoscopic PVI posterior encircling box lesion without management of the LAA.

III. Alternative approaches to posterior LA wall epicardial ablation lesion (ie, pericardioscopic epicardial debulking ablation procedures "convergent method") without management of the LAA.

The pathophysiologic basis behind the potential validity of targeted epicardial minimally invasive ablation, as a concept, may rest in the failures of catheter-based ablation and in the established AF mechanisms of macro-reentrant rotors degrading to include the complex foci of atrial wall fibrosis as AF duration and persistence increase ${ }^{67-70}$ This is further informed by anatomic substrates that could be the generation of AF as extrapulmonary triggers located in the superior vena cava, the ligament of Marshall, and the epicardial ridge between the left pulmonary vein and the LAA. ${ }^{70}$

Less often performed, stand-alone surgical ablations comprise only $8 \%$ of ablation procedures performed in the Society of Thoracic Surgeons Adult Cardiac Surgery Database. ${ }^{71}$ Nevertheless, the ability to provide minimally invasive epicardial ablation procedures without the need for cardiopulmonary bypass or sternotomy remains an attractive option for patients and electrophysiologists. In fact, a recent review demonstrated the Cox-Maze procedure is the most effective minimally invasive surgical strategy for the treatment of stand-alone AF. ${ }^{65}$ Each of the 3 categories of hybrid ablation techniques will be briefly addressed and available data reviewed. In the future it will be necessary to compare these different techniques to create an evidence-based decision tree for the best surgical approach. However, currently there are insufficient published data comparing these techniques to create such a decision tree. Bilateral pulmonary vein isolation and management of left atrial appendage. The technique of thoracoscopic port-only bilateral epicardial ablation was established a decade ago to be a safe and initially effective strategy to introduce the encircling PVI box lesion using alternative energy sources. ${ }^{72}$ Although energy sources such as microwave proved not to deliver effective lesions, ${ }^{73}$ several groups from around the world have since documented that RF ablation devices applied using this platform can result in good midterm outcomes. ${ }^{74}$ Likewise, the application of an RF clamp to create PVI antral pairs via bilateral thoracotomies has been established as a safe procedure with reasonable short-term efficacy. ${ }^{75}$

It was not until groups, such as those led by Damiano, Melby, and colleagues, ${ }^{76}$ began studying modes of failure of epicardial PVI ablation that we learned of the common occurrence of late gaps in ablation lines despite initial operative confirmation of pulmonary vein exit block. This information established a potential value for combining epicardial PVI with endocardial mapping and ablation. Early experiences with these so-called hybrid approaches included immediate intraoperative or periprocedural catheter-based confirmation of lesions and the application of additional endocardial completion lesions as necessary. ${ }^{77}$ Immediate electrophysiology laboratory assessments of epicardial lesions not only may provide logistic challenges but also may miss late ablation gaps that are electrically unmasked after resolution of the acute inflammatory process of surgical ablation. As such, early results assembled after hybrid ablation revealed freedom from $\mathrm{AF}$ off of $\mathrm{AAD}$ for paroxysmal $\mathrm{AF}$ of $75 \%$, persistent $\mathrm{AF}$ of $67 \%$, and long-standing $\mathrm{AF}$ of $43 \%$. $^{78}$

Several authors have pursued hybrid AF ablation and epicardial LAA exclusion in combination with immediate staged or interval staged electrophysiology catheter-based mapping and treatment. ${ }^{79-84}$ The majority of the available studies are single-institution experiences describing cases of heterogeneous AF types.

The group from Maastricht, led by La Meir and Pison, has been a pioneer in this field. ${ }^{79-81}$ By using a bipolar RF clamp and a linear RF pen (AtriCure Inc, Mason, Ohio), they diligently performed epicardial bilateral antral PVI, box lesion, mitral isthmus line, coronary sinus lesion, and superior vena cava isolation concluding with LAA staple exclusion. This was followed by immediate staged catheter-based analysis using rapid atrial pacing induction. In their total of 78 patients from 2009 to 2012, $28(36 \%)$ required endocardial completion of posterior LA lesions and 10 required mitral line adjustment. There was no 30-day mortality, and 6 patients had major complications. Their 1-year freedom from $\mathrm{AF}$ and $\mathrm{AAD}$ measured by 7 -day Holter was $87 \%$ overall and $87 \%$ (43/49) for patients with persistent AF.

Mahapatra and colleagues ${ }^{82}$ reported on 15 patients with persistent $\mathrm{AF}$ in whom they performed the same lesions with the same energy source (AtriCure Inc), but with a staged catheter-based assessment of 4 to 5 days. They found that 4 of $15(27 \%)$ had gaps in the roof line and mitral lines requiring endocardial consolidation, as well as ablation of 
inducible flutter, to result in a 1-year freedom from $\mathrm{AF}$ and AAD measured by 7-day Holter in 13 of the 14 patients followed $(93 \%)$.

Kurfirst and colleagues ${ }^{83}$ performed bilateral PVI box lesion and an additional roof line with the bipolar clamp and RF pen (AtriCure Inc) and LAA exclusion with clips in 30 patients with persistent AF. Of note, they chose to perform the catheter-based component of the hybrid procedure at 3 months postoperatively, and they found that gaps occurred in $77 \%$ to $87 \%$ of the PVI lesions, approximately $70 \%$ of the roof lines, and $40 \%$ of the floor lines requiring endocardial line consolidation. Nevertheless, they were able to obtain a 1-year freedom from $\mathrm{AF}$ and $\mathrm{AAD}$ measured by 7 -day Holter of $90 \%$ (27/30).

Lee and colleagues ${ }^{84}$ applied a RF Cardioblate Gemini-X clamp (Medtronic, Minneapolis, Minn) to perform bilateral PVI only and LAA staple exclusion in 25 patients. Catheter-based assessment was performed in only 7 patients in a delayed interval of more than 3 months based on recurrence of AF to find that all 7 had pulmonary vein reconnection requiring endocardial ablation and completion of mitral lines. The 1-year freedom from AF and AAD measured by 7-day Holter was achieved in 12 of 23 patients $(52 \%)$.

Unilateral thoracoscopic pulmonary vein isolation encircling lesion without left atrial appendage exclusion. A unilateral thoracoscopic technique to encircle the pulmonary veins as a circumferential box lesion has been developed using the unipolar RF suction Estech Cobra Adhere XL device (AtriCure, Inc).

La Meir and colleagues ${ }^{85}$ applied this technique to 19 patients with mixed AF type followed by immediate staged hybrid catheter-based assessment to find that all 19 had gaps in the box lesion requiring ablation along with mitral line completion, and only 7 of $19(36 \%)$ had 1-year freedom from $\mathrm{AF}$ and $\mathrm{AAD}$.

Bisleri and colleagues ${ }^{86}$ used the same approach in 45 patients with persistent AF, but with a delayed staged hybrid catheter-based assessment at 30 to 45 days postoperatively. They found pulmonary vein reconnections in only 3 of 45 patients $(7 \%)$. They measured 1-year freedom from AF and AAD with an implantable loop recorder defined as AF over 5 minutes or overall burden of more than $0.5 \%$, which occurred in 40 of $45(89 \%)$ of their patients.

Epicardial pericardioscopic posterior left atrial ablation ("convergent procedure") without left atrial appendage exclusion. A novel approach to epicardial LA ablation has been recently explored with a vacuumirrigated unipolar RF device delivered via laparoscopic transdiaphragmatic pericardioscopy using the Numeris Guided Coagulation System with VisiTrax (AtriCure Inc). This technique avoids entry into the thoracic cavity altogether to provide nonencircling bilateral posterior antral lesions, a posterior box lesion, a mitral isthmus line, a coronary sinus lesion, and an additional roof line, but this does not permit LAA exclusion. The inferior and posterior left atrial surfaces may be well visualized, but the superior and anterior lesions are applied without direct visualization, especially at the pericardial reflections. This "convergent" approach permits a debulking of the posterior LA.

Gehi and colleagues ${ }^{87}$ reported a series of 101 patients with AF heterogeneity using this procedure followed by immediate staged catheter-based assessment and found PVI gaps in only $4 \%$, but additional roof lines and completion lines to the mitral isthmus were required in $90 \%$ of patients. They had 2 operative mortalities and 7 major complications and achieved a 24-hour Holter documented 1-year freedom from AF and AAD in 46/69 $(67 \%)$. Geršak and colleagues ${ }^{88}$ reported a multiinstitutional European experience with the convergent procedure in 73 patients with persistent AF with mixed intervals of staged catheter-based assessment, but found PVI gaps in all patients at the pericardial reflections. Edgerton and colleagues ${ }^{89}$ applied this procedure in 24 patients with persistent $\mathrm{AF}$ and found that $19 \%$ were free of $\mathrm{AF}$ and $\mathrm{AAD}$ at 24 months, but 3 patients died $(12.5 \%), 4.2 \%$ of patients had an acute stroke, and 1 patient had an atrioesophageal fistula. These results led them to conclude that this procedure does not improve outcomes in patients with a larger LA and persistent $\mathrm{AF}$, and there was evidence that this combined surgical/endocardial ablation approach increased complication rates and did not improve outcomes when compared with extensive endocardial ablation only. ${ }^{89}$

\section{AIM 3. Ablation Tools}

Research Question 6: Which surgical ablation devices are associated with reliable transmural lesions?

Recommendation \#9. The best evidence exists for the use of bipolar RF clamps and cryoablation devices, which have become integral parts of many procedures, including PVI and the Cox-Maze IV procedure. The use of epicardial unipolar RF or unidirectional bipolar RF ablation outside of clinical trials is not recommended, because its efficacy remains questionable.

Reasoning. Ablation devices have revolutionized the surgical treatment of AF. The best evidence exists for the use of bipolar RF clamps and cryoablation devices, which have become an integral part of many procedures, including the Cox-Maze IV. ${ }^{90}$ We do not recommend the use of epicardial unipolar RF ablation outside clinical trials, because its efficacy is questionable. Cryoablation is most effective when used on an empty heart, especially when it is applied endocardially. Full beating-heart epicardial 
cryoablation is not recommended, because the heat-sink effect of circulating blood can render this technique ineffective. ${ }^{91}$ Further research is necessary to produce devices that can safely complete a full Cox-Maze lesion set on the beating heart. The following general recommendations are given on the basis of available experimental and clinical evidence:

a. Empty arrested or beating heart: Recommended ablation devices for PVI are bipolar RF clamps or reusable/ disposable cryoprobes.

b. Beating heart: Bipolar RF clamps are effective to isolate pulmonary veins and recommended with mandatory testing for exit or entrance block.

c. Beating heart: Surface bipolar RF devices may be recommended for free wall linear ablation when lesion integrity can be tested, and multiple applications are recommended to achieve adequate lesion depth. However, consistency of the lesion is unpredictable.

d. Beating heart: Epicardial cryoablation is not recommended, but endocardial cryoablation is recommended for free wall linear ablation because of the high degree of transmurality.

e. Clinical trials of hybrid procedures: only settings where epicardial unipolar RF devices may be applied provided it is accompanied by acute lesion integrity testing.

f. When ablating with any device, coronary arteries should be identified and avoided.

Reasoning. Over the last 15 years, the surgical treatment of AF has been transformed by the introduction of ablation devices to replace most of the incisions used in the original Cox-Maze procedure. ${ }^{6,7}$ Numerous technologies have been developed and tested both in animal models and in prospective clinical trials and retrospective case series. Current clinically available ablation devices use unipolar or bipolar RF energy or cryothermal energy. Of note, there is only 1 device that carries a specific indication for ablation of AF; the remainder are approved by the Federal Drug Administration (FDA) approved only for ablation of cardiac tissue.

Current devices for surgical ablation of AF use RF or cryothermal energy to ablate cardiac tissue. RF ablation requires heating cardiac tissue to a temperature between $50^{\circ} \mathrm{C}$ and $100^{\circ} \mathrm{C}$ to cause coagulative necrosis. Both unipolar and bipolar RF devices are available. Cryoablation uses evaporative cooling to freeze cardiac tissue, leading to tissue necrosis. The available systems use nitrous oxide or argon as the refrigerant.

Bipolar radiofrequency clamps. In these devices, the electrodes are embedded in the jaws of the clamp. There are also bipolar linear devices in which the electrodes are made to be placed on the endocardial or epicardial surface.

There are nonirrigated impedance-controlled dual electrode systems. It is the only FDA-approved device with a specific indication for ablation of cardiac tissue for treatment of persistent or long-standing persistent $\mathrm{AF}$ during a concomitant procedure. Ablation should be performed until the audible tone becomes intermittent, which occurs when conductance reaches a stable minimal value. In a chronic porcine study, all lesions produced in this manner were transmural. ${ }^{92} \mathrm{~A}$ version of this device has been modified for thoracoscopic use.

Care needs to be taken when using nonirrigated bipolar RF clamps. The electrodes need to be cleaned after every 2 to 3 ablations, because char decreases conductance, which will result in inadequate ablation. Other factors, such as air, fat, intraluminal catheters or electrodes, and other inanimate objects, also will decrease conductance and limit ablation depth. All of these should be avoided, and the electrodes need to firmly clamp the tissue without folding or imbricating the atria to be effective.

There are also irrigated impedance-controlled bipolar RF clamps. Irrigation is thought to increase the size of lesions by limiting char. These devices were evaluated in porcine models in 2 independent laboratories and showed a high rate of transmural lesion formation, up to $99 \%$ at 30 days. $^{76,93}$ Irrigated clamps do not need to be cleaned because the irrigation prevents char formation. However, the same precautions need to be taken to avoid factors that decrease conductance, as stated earlier.

Surface bipolar devices. There are 3 surface bipolar RF devices available. These devices can be applied epicardially or endocardially. Ablation times range from 10 to 40 seconds per the manufacturer's instructions. Continuous lesions should be overlapped, because the highest risk of an ablation gap is at the end of the device. These devices have shown variable results. The Isolator linear pen (AtriCure Inc) showed only a $64 \%$ overall rate of transmural lesion formation with an $11 \%$ rate of tissue perforation in an acute porcine model. ${ }^{94}$ The Isolator multifunctional pen showed transmural lesion formation in 10 seconds in tissues less than $4 \mathrm{~mm}$ thick but had a maximum depth of penetration of only $6.1 \mathrm{~mm} .{ }^{8}$ The Coolrail linear pen (AtriCure Inc) produced transmurality in $76 \%$ of lesions at 4 weeks in a porcine beating-heart model,,${ }^{95,96}$ but was incapable of creating conduction block in a chronic animal model. ${ }^{96}$

The COBRA Fusion 150 and 50 (AtriCure Inc) are suction-assisted, temperature-controlled combined bipolar and unipolar RF devices. These should be applied with $-500 \mathrm{~mm} \mathrm{Hg}$ vacuum and 60 to 120 seconds depending on the thickness of the tissue and the desired temperature per the manufacturer's instructions. This system was shown to produce transmural lesions in $94 \%$ of cross-sections evaluated in an acute porcine model, although only $68 \%$ of lesions were transmural throughout their length. ${ }^{97}$

Unipolar radiofrequency devices. In general, unipolar epicardial RF ablation has shown poor efficacy for the 
creation of transmural lesions. However, several devices remain on the market. The Cardioblate irrigated pen (Medtronic, Minneapolis, Minn) was evaluated in an in vitro model that showed superior lesion size compared with conventional unipolar ablation, such as that found in the Cardioblate MAPS device (Medtronic). ${ }^{98}$ The EPi-Sense Coagulation System with VisiTrax (AtriCure Inc) is a suction- and perfusion-assisted unipolar RF device produced in 3 lengths $(1-3 \mathrm{~cm})$. The results of animal studies with the AtriCure device have been variable. One acute ovine study showed a $100 \%$ rate of transmural lesions, ${ }^{99}$ but a porcine acute study showed only a $15 \%$ rate of transmural lesions. ${ }^{96}$

Cryoablation devices. Two manufacturers currently produce cryoablation devices for surgical cardiac ablation. The cryoICE system (AtriCure Inc) uses nitrous oxide to freeze tissue with a minimal probe temperature of $-50^{\circ} \mathrm{C}$ to $-70^{\circ} \mathrm{C}$. Approximately all (83/84) lesions produced using 2 minutes of cryoablation with this system were transmural in a chronic porcine study. ${ }^{100}$ The Cardioblate CryoFlex, CryoFlex 10-S, and CryoFlex clamps (Medtronic) all use argon as the refrigerant, reaching up to $-160^{\circ} \mathrm{C}$. All are disposable. The CryoFlex clamp produced a $93 \%$ rate of transmural lesions in a chronic canine model. ${ }^{101}$ The same study evaluated linear epicardial lesions produced using the CryoFlex system; only $84 \%$ of linear lesions were transmural after 180 seconds of ablation. Both technologies use malleable disposable cryoprobes that can be shaped to facilitate minimally invasive use.

Ablation should be performed by surgeons with appropriate training and experience. Except within the context of clinical trials, only devices with proven efficacy should be used. When possible, the presence of acute conduction block should be used to confirm ablation efficacy. This is done by testing for exit or entrance block by pacing/sensing from the right and left pulmonary veins.

Ablation devices ideally should be evaluated prospectively in an independent laboratory with submission of results to peer-reviewed journals. Devices should be tested clinically using previously evaluated lesion sets to minimize confusion. Clinical follow-up data collected according to current guidelines should be the gold standard for evaluating a device's effectiveness. Ablation success is defined as freedom from atrial tachyarrhythmias and AADs at 12 months. ${ }^{3}$

\section{AIM 4. Training}

Research Question 7: Should surgeons performing surgical ablation be required to undergo basic training and education?

Recommendation \#10. Surgical ablation procedures should require basic training, proctoring, and education to improve the surgeon's understanding of AF, the surgical options, and the improved outcomes. Training and education should be completed before the performance of surgical ablation. We highly recommend surgeons who are new to surgical AF be proctored by an experienced surgeon for 3 to 5 cases before performing surgical ablation alone (Class I, Level C).

Reasoning. Currently, there are no validated training plans or curricula for surgeons to complete before performing surgical ablation of AF. Although surgical procedures to treat $\mathrm{AF}$ were developed more than 3 decades ago, surgeons' approach to this problem has been widely varied. The introduction of new ablation technologies and the creation of a large number of different lesion sets have added to the complexity and confusion surrounding surgical ablation of AF. It is clear that training and surgical experience influence both the use of surgical ablation and the results. ${ }^{9,43,102}$ With increasing experience, surgeons are more likely to perform an ablation in patients with preexisting AF. As with any other cardiac surgical procedure, the percent of patients undergoing surgical ablation and the success of such procedures may be superior when performed by experienced and well-trained cardiac surgeons. ${ }^{9}$ Optimization of patient outcomes requires a combination of education and formal training that incorporates understanding of (1) the risks associated with leaving AF untreated; (2) the risks associated with surgical ablation; (3) the recommended procedure, including choice of lesion set and ablation technologies; and (4) the results of surgical ablation.

Risks associated with untreated atrial fibrillation. It is axiomatic that surgeons should understand the conditions for which they are treating patients. Cardiac surgical patients with preexisting AF have reduced long-term survival if the AF is left untreated. ${ }^{45}$ This holds true whether the patient's primary indication for surgery is valvular heart disease or coronary artery disease. Careful analysis of the results of surgical ablation of AF suggests that successful AF ablation may improve survival. ${ }^{103}$ In addition, AF-related strokes are rare in patients who have undergone surgical ablation of AF. It has been argued that this finding could be related to LAA ligation, which is anticipated to be addressed by the Left Atrial Appendage Occlusion Study III, which is currently under way. ${ }^{104}$ Understanding the risks of untreated AF should prompt surgeons to consider AF ablation in all cardiac surgical patients presenting with AF. Risks associated with treating atrial fibrillation. Our extensive summary indicates that perioperative morbidity including stroke is not increased with the addition of surgical ablation, and we further found a short-term survival benefit. Surgeons must understand that the addition of surgical ablation does not increase the risk of major morbidity or mortality. ${ }^{10}$ Multiple studies confirm that surgical 
ablation is safe. ${ }^{9,10,43,45,102,103,105}$ Although surgical ablation does increase aortic crossclamp and cardiopulmonary bypass times, this does not translate into increased patient risk. Surgical ablation may increase the risk of requiring a permanent pacemaker, but in most studies this risk is small. ${ }^{10,43,102}$

Recommended ablation procedure. Results of the cut-andsew Cox-Maze III procedure were excellent; therefore, this procedure should serve as the predicate for surgical ablation with new energy sources. All surgeons should understand the biatrial lesion sets of the Cox-Maze III and energy-assisted Cox-Maze IV procedures. Key components include isolation of the entire posterior LA (including the pulmonary veins), a connecting lesion to the mitral annulus that includes the coronary sinus, management of the LAA, and at least 1 right atrial lesion that reaches the tricuspid annulus.

Although a recent randomized controlled clinical trial provided some data concerning the biatrial lesion set versus a left atrial lesion set in patients with persistent and longstanding persistent $\mathrm{AF}$, the trial was not powered to confirm that a left atrial lesion set alone is equivalent to a biatrial lesion set in such patients. ${ }^{10}$ It may be appropriate to use a left atrial lesion set alone in selected patients with paroxysmal AF and normal left atrial size.

Once the surgeon is thoroughly versed in the choice of lesion set, he or she must understand the appropriate use of ablation technology. This requires that the surgeon invest adequate time in understanding the technology and observe at least 1 surgical case using the particular ablation technology. It is further advisable that the surgeon be proctored for his or her first ablation case. Surgeons should avail themselves of proctorship(s) made available by any company that has FDA-approved technology for AF ablation. The surgeon must understand proper lesion placement and pitfalls of ablation technologies (eg, gaps, bunching of tissue, inadequate duration of freeze-thaw cycles, failure to clean the jaws of bipolar clamps). Once the surgeon has completed training, he/she may begin performing AF ablation. The surgeon should keep a log of $\mathrm{AF}$ ablation cases because this will aid in tabulating results (discussed later).

Results of surgical ablation. Before performing surgical ablation of AF, the surgeon must be well versed in the expected results. In general, freedom from $\mathrm{AF}$ at 1 year should be $70 \%$ or greater; selected experts report success rates of $80 \%$ to $90 \%{ }^{9,43,45,102,103,105}$ Surgeons should record their own results according to Heart Rhythm Society guidelines; this requires long-term monitoring at the 12-month mark. ${ }^{60}$ Surgeons should record their rate for permanent pacemaker implantation after AF ablation. To achieve the best results, surgeons should be well versed in the perioperative care of these patients. It is not enough to perform a procedure and simply send the patient home. Successful ablation begins in the operating room but requires continued monitoring and medical management to achieve normal sinus rhythm. Many patients require postoperative antiarrhythmic therapy and electrical cardioversion. The surgeon must understand that successful ablation occurs over time and requires effort.

Currently, there is no specific training that is required before a surgeon performs surgical ablation. It may be necessary to establish credentialing criteria for surgeons wanting to perform surgical ablation with novel technologies, including both proctoring and mentoring protocols in the operating room. Training and mentoring are essential for this technique to be implemented with the best possible outcomes for the patients.

Therefore, we recommend that training and education be completed before the performance of surgical ablation. This training and education should aim to provide surgeons with the following ${ }^{64}$ :

1. Knowledge in atrial anatomy and appropriate patient selection

2. Basic understanding of the significance of the different lesion sets

3. Knowledge in the intraprocedural management of patients in terms of avoidance of complications and their treatment

4. Knowledge and understanding in postprocedural management and follow-up

It is also highly recommended to include surgical $\mathrm{AF}$ ablation during training. ${ }^{106}$ Previously, it has been recommended to include 30 to 50 ablation cases during training. ${ }^{64,106}$ We recommend that surgical training for surgical ablation should follow this same recommendation. We also highly recommend that surgeons who are new to surgical AF be proctored by an experienced surgeon for 3 to 5 cases before performing surgical ablation alone. In terms of maintenance of proficiency level, surgeons with sufficient training should aim to routinely perform surgical ablation cases.

\section{RECOMMENDATIONS FOR FUTURE AMERICAN ASSOCIATION FOR THORACIC SURGERY EFFORTS}

The task force recommends the establishment of uniform definitions for time points and outcome measures so that systematic analyses can be conducted to more efficiently determine the effectiveness and safety of surgical ablation. In addition, it is recommended that more RCTs are undertaken that are well designed and well controlled with regard to lesion set technology and outcomes.

The clinical areas and studies that are recommended are as follows:

- Well-designed studies to address long-term survival and embolic complications 
- Well-designed studies to develop a better understanding on the cost effectiveness of surgical ablation

- Well-designed studies to assess the role of stand-alone surgical ablation procedures to include a Cox-Maze procedure and off-pump procedures to include the hybrid approach

- Training and education including surgical ablation should be included in the residency curriculum

\section{RECOMMENDATIONS FOR THE USE OF THE GUIDELINES}

These guidelines are best used as a guide for practice and teaching. The applicability of these recommendations to the individual patient should be evaluated on a case-by-case basis and applied only when clinically appropriate. In addition, these guidelines can serve as a tool to guide uniform practices, to guide development of surgeon training protocols, and to form the basis of uniform time points and outcomes for the thoracic surgical community.

The task force received no financial support. The AATS provided teleconferencing and covered the cost of a 1-day face-to-face conference for the participants. The members of this task force had no conflicts of interest related to any of the recommendations made in the current article; all of their other potential conflicts of interest were disclosed in writing.

\section{CONCLUSIONS}

Surgical ablation is a safe and effective strategy for the treatment of AF. It is important to carefully consider the indications for hybrid ablation or the stand-alone off-bypass ablation. Bipolar RF clamps or reusable/disposable cryoprobes are the best ablation devices, but when ablating, coronary arteries should be avoided. Training and mentoring protocols for surgeons interested in performing surgical ablation need to be created to ensure patient safety and beneficial outcomes. Future studies should use standardized time points and outcome measures to enhance the ability to compare outcomes across different studies. Studies designed to measure the impact of surgical ablation for $\mathrm{AF}$ on stroke rate and survival should include a minimum of 3 to 5 years of follow-up.

\section{Conflict of Interest Statement}

N.A. is a consultant for Medtronic, a member of the speaker's bureau for AtriCure, proctor and member of the speaker's bureau for LivaNova, on the advisory board for Nido Surgical, and a co-owner of Left Atrial Appendage Occlusion, LLC. R.J.D. reports consulting fees from Atricure, lecture fees and grant support from Edwards and On-X Lifesciences, and grant support from Thrasos Inc. V.B. reports uncompensated work on the Mitral Advisory Board for Abbott Cardiovascular. H.C. reports consulting fees for Atricure and Medtronic, and advisory board work for Medtronic. M.L. is a consultant for AtriCure. N.D. is a consultant for AtriCure. M.G. reports personal fees from Edwards Lifesciences, personal fees from Medtronic, personal fees from On-X, grants and personal fees from St. Jude Medical, personal fees from Abbott, personal fees and other from AtriCure, and personal fees from ClearFlow. All other authors have nothing to disclose with regard to commercial support.

\section{References}

1. Cox JL, Boineau JP, Schuessler RB, Ferguson TB, Cain ME, Lindsay BD, et al Successful surgical treatment of atrial fibrillation. Review and clinical update. JAMA. 1991;266:1976-80.

2. Cox JL, Schuessler RB, Lappas DG, Boineau JP. An 8 1/2-year clinical experience with surgery for atrial fibrillation. Ann Surg. 1996;224:267-75.

3. Millar RC, Arcidi JM, Alison PJ. The maze III procedure for atrial fibrillation: should the indications be expanded? Ann Thorac Surg. 2000;70:1580-6.

4. Cox JL, Ad N. The importance of cryoablation of the coronary sinus during the Maze procedure. Semin Thorac Cardiovasc Surg. 2000;12:20-4.

5. Patwardhan AM, Dave HH, Tamhane AA, Pandit SP, Dalvi BV, Golam K, et al Intraoperative radiofrequency microbipolar coagulation to replace incisions of maze III procedure for correcting atrial fibrillation in patients with rheumatic valvular disease. Eur J Cardiothorac Surg. 1997;12:627-33.

6. Gaynor SL, Diodato MD, Prasad SM, Ishii Y, Schuessler RB, Bailey MS, et al. A prospective, single-center clinical trial of a modified Cox maze procedure with bipolar radiofrequency ablation. J Thorac Cardiovasc Surg. 2004;128:535-42.

7. Mokadam NA, McCarthy PM, Gillinov AM, Ryan WH, Moon MR, Mack MJ, et al. A prospective multicenter trial of bipolar radiofrequency ablation for atrial fibrillation: early results. Ann Thorac Surg. 2004;78:1665-70.

8. Gillinov AM, Bhavani S, Blackstone EH, Rajeswaran J, Svensson LG, Navia JL, et al. Surgery for permanent atrial fibrillation: impact of patient factors and lesion set. Ann Thorac Surg. 2006;82:502-14.

9. Ad N, Henry L, Hunt S, Holmes SD. Impact of clinical presentation and surgeon experience on the decision to perform surgical ablation. Ann Thorac Surg. 2013; 96:763-9.

10. Gillinov AM, Gelijns AC, Parides MK, DeRose JJ, Moskowitz AJ, Voisine P, et al. Surgical ablation of atrial fibrillation during mitral-valve surgery. $N$ Engl J Med. 2015;372:1399-409.

11. Cherniavsky A, Kareva Y, Pak I, Rakhmonov S, Pokushalov E, Romanov A, et al. Assessment of results of surgical treatment for persistent atrial fibrillation during coronary artery bypass grafting using implantable loop recorders. Interact Cardiovasc Thorac Surg. 2014;18:727-31.

12. Yoo JS, Kim JB, Ro SK, Jung Y, Jung S-H, Choo SJ, et al. Impact of concomitant surgical atrial fibrillation ablation in patients undergoing aortic valve replacement. Circ J Off J Jpn Circ Soc. 2014;78:1364-71.

13. Ad N, Holmes SD, Massimiano PS, Pritchard G, Stone LE, Henry L. The effect of the Cox-maze procedure for atrial fibrillation concomitant to mitral and tricuspid valve surgery. J Thorac Cardiovasc Surg. 2013;146:1426-35.

14. Saint LL, Damiano RJ, Cuculich PS, Guthrie TJ, Moon MR, Munfakh NA, et al. Incremental risk of the Cox-maze IV procedure for patients with atrial fibrillation undergoing mitral valve surgery. J Thorac Cardiovasc Surg. 2013;146:1072-7.

15. McCarthy PM, Manjunath A, Kruse J, Andrei A-C, Li Z, McGee EC, et al. Should paroxysmal atrial fibrillation be treated during cardiac surgery? J Thorac Cardiovasc Surg. 2013;146:810-23.

16. Attaran S, Saleh HZ, Shaw M, Ward A, Pullan M, Fabri BM. Does the outcome improve after radiofrequency ablation for atrial fibrillation in patients undergoing cardiac surgery? A propensity-matched comparison. Eur J Cardiothorac Surg. 2012;41:806-11.

17. Boersma LVA, Castella M, van Boven W, Berruezo A, Yilmaz A, Nadal M, et al Atrial fibrillation catheter ablation versus surgical ablation treatment (FAST): a 2-center randomized clinical trial. Circulation. 2012;125:23-30.

18. Budera P, Straka Z, Osmančík P, Vaněk T, Jelínek Š, Hlavička J, et al. Comparison of cardiac surgery with left atrial surgical ablation vs. cardiac surgery without atrial ablation in patients with coronary and/or valvular heart disease plus atrial fibrillation: final results of the PRAGUE-12 randomized multicentre study. Eur Heart J. 2012;33:2644-52. 
19. Bum Kim J, Suk Moon J, Yun S-C, Kee Kim W, Jung S-H, Jung Choo S, et al. Long-term outcomes of mechanical valve replacement in patients with atrial fibrillation: impact of the maze procedure. Circulation. 2012;125:2071-80.

20. Malaisrie SC, Lee R, Kruse J, Lapin B, Wang EC, Bonow RO, et al. Atrial fibrillation ablation in patients undergoing aortic valve replacement. J Heart Valve Dis. 2012;21:350-7.

21. Liu X, Tan H-W, Wang X-H, Shi H-F, Li Y-Z, Li F, et al. Efficacy of catheter ablation and surgical CryoMaze procedure in patients with long-lasting persistent atrial fibrillation and rheumatic heart disease: a randomized trial. Eur Heart J. 2010;31:2633-41.

22. Albrecht A, Kalil RAK, Schuch L, Abrahão R, Sant'Anna JRM, de Lima G, et al. Randomized study of surgical isolation of the pulmonary veins for correction of permanent atrial fibrillation associated with mitral valve disease. $J$ Thorac Cardiovasc Surg. 2009;138:454-9.

23. Chevalier P, Leizorovicz A, Maureira P, Carteaux J-P, Corbineau H, Caus T, et al. Left atrial radiofrequency ablation during mitral valve surgery: a prospective randomized multicentre study (SAFIR). Arch Cardiovasc Dis. 2009;102: 769-75.

24. von Oppell UO, Masani N, O'Callaghan P, Wheeler R, Dimitrakakis G, Schiffelers S. Mitral valve surgery plus concomitant atrial fibrillation ablation is superior to mitral valve surgery alone with an intensive rhythm control strategy. Eur J Cardiothorac Surg. 2009;35:641-50.

25. Srivastava V, Kumar S, Javali S, Rajesh TR, Pai V, Khandekar J, et al Efficacy of three different ablative procedures to treat atrial fibrillation in patients with valvular heart disease: a randomised trial. Heart Lung Circ. 2008; 17:232-40.

26. Blomström-Lundqvist C, Johansson B, Berglin E, Nilsson L, Jensen SM, Thelin S, et al. A randomized double-blind study of epicardial left atrial cryoablation for permanent atrial fibrillation in patients undergoing mitral valve surgery: the SWEDish Multicentre Atrial Fibrillation study (SWEDMAF). Eur Heart J. 2007;28:2902-8.

27. Abreu Filho CAC, Lisboa LAF, Dallan LAO, Spina GS, Grinberg M, Scanavacca M, et al. Effectiveness of the maze procedure using cooled-tip radiofrequency ablation in patients with permanent atrial fibrillation and rheumatic mitral valve disease. Circulation. 2005;112(9 Suppl):I20-5.

28. Doukas G, Samani NJ, Alexiou C, Oc M, Chin DT, Stafford PG, et al. Left atrial radiofrequency ablation during mitral valve surgery for continuous atrial fibrillation: a randomized controlled trial. JAMA. 2005;294:2323-9.

29. de Lima GG, Kalil RAK, Leiria TLL, Hatem DM, Kruse CL, Abrahão R, et al. Randomized study of surgery for patients with permanent atrial fibrillation as a result of mitral valve disease. Ann Thorac Surg. 2004;77:2089-95.

30. Nakajima H, Kobayashi J, Bando K, Yasumura Y, Nakatani S, Kimura K, et al Consequence of atrial fibrillation and the risk of embolism after percutaneous mitral commissurotomy: the necessity of the maze procedure. Ann Thorac Surg. 2004;78:800-5.

31. Vasconcelos JT, Scanavacca MI, Sampaio RO, Grinberg M, Sosa EA, Oliveira SA. Surgical treatment of atrial fibrillation through isolation of the left atrial posterior wall in patients with chronic rheumatic mitral valve disease. A randomized study with control group. Arq Bras Cardiol. 2004;83:211-8, 203-10.

32. Akpinar B, Guden M, Sagbas E, Sanisoglu I, Ozbek U, Caynak B, et al. Combined radiofrequency modified maze and mitral valve procedure through a port access approach: early and mid-term results. Eur J Cardiothorac Surg. 2003;24: 223-30.

33. Jessurun ER, van Hemel NM, Defauw JJ, Brutel De La Rivière A, Stofmeel MA, Kelder JC, et al. A randomized study of combining maze surgery for atrial fibrillation with mitral valve surgery. J Cardiovasc Surg (Torino) 2003;44:9-18

34. Schuetz A, Schulze CJ, Sarvanakis KK, Mair H, Plazer H, Kilger E, et al. Surgical treatment of permanent atrial fibrillation using microwave energy ablation: a prospective randomized clinical trial. Eur J Cardiothorac Surg. 2003 24:475-80.

35. Raanani E, Albage A, David TE, Yau TM, Armstrong S. The efficacy of the Cox/maze procedure combined with mitral valve surgery: a matched control study. Eur J Cardiothorac Surg. 2001;19:438-42.

36. Jatene MB, Marcial MB, Tarasoutchi F, Cardoso RA, Pomerantzeff P, Jatene AD. Influence of the maze procedure on the treatment of rheumatic atrial fibrillation - evaluation of rhythm control and clinical outcome in a comparative study. Eur J Cardiothorac Surg. 2000;17:117-24.

37. Pokushalov E, Romanov A, Corbucci G, Cherniavsky A, Karaskov A Benefit of ablation of first diagnosed paroxysmal atrial fibrillation during coronary artery bypass grafting: a pilot study. Eur J Cardiothorac Surg. 2012 41:556-60.

38. Wang J, Li Y, Shi J, Han J, Xu C, Ma C, et al. Minimally invasive surgical versus catheter ablation for the long-lasting persistent atrial fibrillation. PloS One. 2011;6:e22122.

39. Johansson B, Houltz B, Berglin E, Brandrup-Wognsen G, Karlsson T, Edvardsson N. Short-term sinus rhythm predicts long-term sinus rhythm and clinical improvement after intraoperative ablation of atrial fibrillation. Europace. 2008;10:610-7.

40. Bando K, Kasegawa H, Okada Y, Kobayashi J, Kada A, Shimokawa T, et al Impact of preoperative and postoperative atrial fibrillation on outcome after mitral valvuloplasty for nonischemic mitral regurgitation. J Thorac Cardiovasc Surg. 2005;129:1032-40.

41. Mantovan R, Raviele A, Buja G, Bertaglia E, Cesari F, Pedrocco A, et al. Left atrial radiofrequency ablation during cardiac surgery in patients with atrial fibrillation. J Cardiovasc Electrophysiol. 2003;14:1289-95.

42. Deneke T, Khargi K, Grewe PH, Laczkovics A, von Dryander S, Lawo T, et al Efficacy of an additional MAZE procedure using cooled-tip radiofrequency ablation in patients with chronic atrial fibrillation and mitral valve disease. A randomized, prospective trial. Eur Heart J. 2002;23:558-66.

43. Ad N, Holmes SD, Pritchard G, Shuman DJ. Association of operative risk with the outcome of concomitant Cox Maze procedure: a comparison of results across risk groups. J Thorac Cardiovasc Surg. 2014;148:3027-33.

44. Bakker RC, Akin S, Rizopoulos D, Kik C, Takkenberg JJM, Bogers AJJC Results of clinical application of the modified maze procedure as concomitant surgery. Interact Cardiovasc Thorac Surg. 2013;16:151-6.

45. Ad N, Henry L, Hunt S, Holmes SD. Do we increase the operative risk by adding the Cox Maze III procedure to aortic valve replacement and coronary artery bypass surgery? J Thorac Cardiovasc Surg. 2012;143:936-44.

46. Grubitzsch H, Dushe S, Beholz S, Dohmen PM, Konertz W. Surgical ablation of atrial fibrillation in patients with congestive heart failure. J Card Fail. 2007;13: 509-16.

47. Forlani S, De Paulis R, Guerrieri Wolf L, Greco R, Polisca P, Moscarelli M, et al Conversion to sinus rhythm by ablation improves quality of life in patients submitted to mitral valve surgery. Ann Thorac Surg. 2006;81:863-7.

48. Kim HJ, Kim JB, Jung SH, Choo SJ, Chung CH, Lee JW. Valve replacement surgery for older individuals with preoperative atrial fibrillation: the effect of prosthetic valve choice and surgical ablation. J Thorac Cardiovasc Surg. 2014; $147: 1907-17$

49. Wang X, Wang X, Song Y, Hu S, Wang W. Efficiency of radiofrequency ablation for surgical treatment of chronic atrial fibrillation in rheumatic valvular disease. Int J Cardiol. 2014; 174:497-502.

50. Knaut M, Kolberg S, Brose S, Jung F. Epicardial microwave ablation of permanent atrial fibrillation during a coronary bypass and/or aortic valve operation prospective, randomised, controlled, mono-centric study. Appl Cardiopulm Pathophysiol. 2010;14:220-8

51. Van Breugel HNaM, Nieman FHM, Accord RE, Van Mastrigt GaPG, Nijs JFMA, Severens JL, et al. A prospective randomized multicenter comparison on health-related quality of life: the value of add-on arrhythmia surgery in patients with paroxysmal, permanent or persistent atrial fibrillation undergoing valvular and/or coronary bypass surgery. $J$ Cardiovasc Electrophysiol. 2010;21:511-20.

52. Louagie Y, Buche M, Eucher P, Schoevaerdts J-C, Gerard M, Jamart J, et al. Improved patient survival with concomitant Cox Maze III procedure compared with heart surgery alone. Ann Thorac Surg. 2009;87:440-6.

53. Stulak JM, Schaff HV, Dearani JA, Orszulak TA, Daly RC, Sundt TM. Restoration of sinus rhythm by the Maze procedure halts progression of tricuspid regurgitation after mitral surgery. Ann Thorac Surg. 2008;86:40-5.

54. Knaut M, Tugtekin SM, Spitzer S, Jung F, Matschke K. Mortality after cardiac surgery with or without microwave ablation in patients with permanent atrial fibrillation. J Heart Valve Dis. 2005;14:531-7.

55. Guang Y, Zhen-jie C, Yong LW, Tong L, Ying L. Evaluation of clinical treatment of atrial fibrillation associated with rheumatic mitral valve disease by radiofrequency ablation. Eur J Cardiothorac Surg. 2002;21: 249-54.

56. Chen MC, Chang JP, Guo GB, Chang HW. Atrial size reduction as a predictor of the success of radiofrequency maze procedure for chronic atrial fibrillation in patients undergoing concomitant valvular surgery. J Cardiovasc Electrophysiol. 2001:12:867-74.

57. Araki Y, Oshima H, Usui A, Ueda Y. Long-term results of the Maze procedure in patients with mechanical valve. Gen Thorac Cardiovasc Surg. 2012;60:326-33. 
58. Amsterdam EA, Wenger NK, Brindis RG, Casey DE, Ganiats TG, Holmes DR, et al. 2014 AHA/ACC Guideline for the Management of Patients With Non-STElevation Acute Coronary Syndromes A Report of the American College of Cardiology/American Heart Association Task Force on Practice Guidelines. Circulation. 2014;130:e344-426.

59. Feinberg WM, Blackshear JL, Laupacis A, Kronmal R, Hart RG. Prevalence, age distribution, and gender of patients with atrial fibrillation. Analysis and implications. Arch Intern Med. 1995;155:469-73.

60. January CT, Wann LS, Alpert JS, Calkins H, Cigarroa JE, Cleveland JC, et al. 2014 AHA/ACC/HRS guideline for the management of patients with atrial fibrillation: executive summary: a report of the American College of Cardiology/American Heart Association Task Force on practice guidelines and the Heart Rhythm Society. Circulation. 2014;130:2071-104.

61. Benjamin EJ, Wolf PA, D’Agostino RB, Silbershatz H, Kannel WB, Levy D. Impact of atrial fibrillation on the risk of death: the Framingham Heart Study. Circulation. 1998;98:946-52.

62. Wolf PA, Abbott RD, Kannel WB. Atrial fibrillation as an independent risk factor for stroke: the Framingham Study. Stroke J Cereb Circ. 1991;22: 983-8.

63. Kim MH, Johnston SS, Chu B-C, Dalal MR, Schulman KL. Estimation of total incremental health care costs in patients with atrial fibrillation in the United States. Circ Cardiovasc Qual Outcomes. 2011;4:313-20.

64. Calkins H, Kuck KH, Cappato R, Brugada J, Camm AJ, Chen S-A, et al. 2012 HRS/EHRA/ECAS expert consensus statement on catheter and surgical ablation of atrial fibrillation: recommendations for patient selection, procedural techniques, patient management and follow-up, definitions, endpoints, and research trial design. Heart Rhythm Off J Heart Rhythm Soc. 2012;9: 632-96.e21.

65. Je HG, Shuman DJ, Ad N. A systematic review of minimally invasive surgical treatment for atrial fibrillation: a comparison of the Cox-Maze procedure, beating-heart epicardial ablation, and the hybrid procedure on safety and efficacy. Eur J Cardiothorac Surg. 2015;48:531-41.

66. La Meir M. Surgical options for treatment of atrial fibrillation. Ann Cardiothorac Surg. 2014;3:30-7.

67. Cox JL, Canavan TE, Schuessler RB, Cain ME, Lindsay BD, Stone C, et al. The surgical treatment of atrial fibrillation. II. Intraoperative electrophysiologic mapping and description of the electrophysiologic basis of atrial flutter and atrial fibrillation. J Thorac Cardiovasc Surg. 1991;101:406-26.

68. Jadidi AS, Cochet H, Shah AJ, Kim SJ, Duncan E, Miyazaki S, et al. Inverse relationship between fractionated electrograms and atrial fibrosis in persistent atrial fibrillation: combined magnetic resonance imaging and high-density mapping. J Am Coll Cardiol. 2013;62:802-12.

69. Badhwar V. Modifying the Cox maze procedure: who should get a U? J Thorac Cardiovasc Surg. 2016;151:1070-2.

70. DeSimone CV, Noheria A, Lachman N, Edwards WD, Gami AS, Maleszewski JJ, et al. Myocardium of the superior vena cava, coronary sinus, vein of Marshall, and the pulmonary vein ostia: gross anatomic studies in 620 hearts. J Cardiovasc Electrophysiol. 2012;23:1304-9.

71. Gammie JS, Haddad M, Milford-Beland S, Welke KF, Ferguson TB, O'Brien SM, et al. Atrial fibrillation correction surgery: lessons from the Society of Thoracic Surgeons National Cardiac Database. Ann Thorac Surg. 2008; 85:909-14.

72. Pruitt JC, Lazzara RR, Dworkin GH, Badhwar V, Kuma C, Ebra G. Totally endoscopic ablation of lone atrial fibrillation: initial clinical experience. Ann Thorac Surg. 2006;81:1325-31.

73. Pruitt JC, Lazzara RR, Ebra G. Minimally invasive surgical ablation of atrial fibrillation: the thoracoscopic box lesion approach. J Interv Card Electrophysiol Int J Arrhythm Pacing. 2007;20:83-7.

74. La Meir M, Gelsomino S, Lucà F, Lorusso R, Gensini GF, Pison L, et al. Minimally invasive thoracoscopic hybrid treatment of lone atrial fibrillation: early results of monopolar versus bipolar radiofrequency source. Interact Cardiovasc Thorac Surg. 2012;14:445-50.

75. Wolf RK, Schneeberger EW, Osterday R, Miller D, Merrill W, Flege JB, et al. Video-assisted bilateral pulmonary vein isolation and left atrial appendage exclusion for atrial fibrillation. J Thorac Cardiovasc Surg. 2005; 130:797-802.

76. Melby SJ, Lee AM, Zierer A, Kaiser SP, Livhits MJ, Boineau JP, et al. Atrial fibrillation propagates through gaps in ablation lines: implications for ablative treatment of atrial fibrillation. Heart Rhythm Off J Heart Rhythm Soc. 2008;5: 1296-301.
77. Krul SPJ, Driessen AHG, van Boven WJ, Linnenbank AC, Geuzebroek GSC, Jackman WM, et al. Thoracoscopic video-assisted pulmonary vein antrum isolation, ganglionated plexus ablation, and periprocedural confirmation of ablation lesions: first results of a hybrid surgical-electrophysiological approach for atrial fibrillation. Circ Arrhythm Electrophysiol. 2011;4:262-70.

78. Pak HN, Hwang C, Lim HE, Kim JS, Kim YH. Hybrid epicardial and endocardial ablation of persistent or permanent atrial fibrillation: a new approach for difficult cases. J Cardiovasc Electrophysiol. 2007;18:917-23.

79. Pison L, Gelsomino S, Lucà F, Parise O, Maessen JG, Crijns HJGM, et al. Effectiveness and safety of simultaneous hybrid thoracoscopic and endocardial catheter ablation of lone atrial fibrillation. Ann Cardiothorac Surg. 2014;3: $38-44$.

80. La Meir M, Gelsomino S, Lucà F, Pison L, Parise O, Colella A, et al. Minimally invasive surgical treatment of lone atrial fibrillation: early results of hybrid versus standard minimally invasive approach employing radiofrequency sources. Int J Cardiol. 2013;167:1469-75.

81. Pison L, La Meir M, van Opstal J, Blaauw Y, Maessen J, Crijns HJ. Hybrid thoracoscopic surgical and transvenous catheter ablation of atrial fibrillation. J Am Coll Cardiol. 2012;60:54-61.

82. Mahapatra S, LaPar DJ, Kamath S, Payne J, Bilchick KC, Mangrum JM, et al. Initial experience of sequential surgical epicardial-catheter endocardial ablation for persistent and long-standing persistent atrial fibrillation with long-term follow-up. Ann Thorac Surg. 2011;91:1890-8.

83. Kurfirst V, Mokraček A, Bulava A, Canadyova J, Haniš J, Pešl L. Two-staged hybrid treatment of persistent atrial fibrillation: short-term single-centre results. Interact Cardiovasc Thorac Surg. 2014;18:451-6.

84. Lee R, McCarthy PM, Passman RS, Kruse J, Malaisrie SC, McGee EC, et al. Surgical treatment for isolated atrial fibrillation: minimally invasive vs. classic cut and sew maze. Innov Phila Pa. 2011;6:373-7.

85. La Meir M, Gelsomino S, Lorusso R, Lucà F, Pison L, Parise O, et al. The hybrid approach for the surgical treatment of lone atrial fibrillation: one-year results employing a monopolar radiofrequency source. J Cardiothorac Surg. 2012;7: 71.

86. Bisleri G, Rosati F, Bontempi L, Curnis A, Muneretto C. Hybrid approach for the treatment of long-standing persistent atrial fibrillation: electrophysiological findings and clinical results. Eur J Cardiothorac Surg. 2013;44:919-23.

87. Gehi AK, Mounsey JP, Pursell I, Landers M, Boyce K, Chung EH, et al. Hybrid epicardial-endocardial ablation using a pericardioscopic technique for the treatment of atrial fibrillation. Heart Rhythm Off J Heart Rhythm Soc. 2013;10:22-8

88. Geršak B, Zembala MO, Müller D, Folliguet T, Jan M, Kowalski O, et al European experience of the convergent atrial fibrillation procedure: multicenter outcomes in consecutive patients. J Thorac Cardiovasc Surg. 2014; 147:1411-6.

89. Edgerton Z, Perini AP, Horton R, Trivedi C, Santangeli P, Bai R, et al. Hybrid procedure (endo/epicardial) versus standard manual ablation in patients undergoing ablation of long-standing persistent atrial fibrillation: results from a single center. J Cardiovasc Electrophysiol. 2016;27:524-30.

90. Robertson JO, Saint LL, Leidenfrost JE, Damiano RJ. Illustrated techniques for performing the Cox-Maze IV procedure through a right mini-thoracotomy. Ann Cardiothorac Surg. 2014;3:105-16.

91. Doll N, Kornherr P, Aupperle H, Fabricius AM, Kiaii B, Ullmann C, et al Epicardial treatment of atrial fibrillation using cryoablation in an acute offpump sheep model. J Thorac Cardiovasc Surg. 2003;51:267-73.

92. Voeller RK, Zierer A, Schuessler RB, Damiano RJ. Performance of a novel dual-electrode bipolar radiofrequency ablation device: a chronic porcine study. Innov Phila Pa. 2011;6:17-22.

93. Bonanomi G, Schwartzman D, Francischelli D, Hebsgaard K, Zenati MA. A new device for beating heart bipolar radiofrequency atrial ablation. $J$ Thorac Cardiovasc Surg. 2003;126:1859-66.

94. Watanabe Y, Weimar T, Kazui T, Lee U, Schuessler RB, Damiano RJ. Epicardial ablation performance of a novel radiofrequency device on the beating heart in pigs. Ann Thorac Surg. 2014;97:673-8.

95. Lee AM, Aziz A, Clark KL, Schuessler RB, Damiano RJ. Chronic performance of a novel radiofrequency ablation device on the beating heart: limitations of conduction delay to assess transmurality. J Thorac Cardiovasc Surg. 2012; 144:859-65.

96. Schuessler RB, Lee AM, Melby SJ, Voeller RK, Gaynor SL, Sakamoto S-I, et al. Animal studies of epicardial atrial ablation. Heart Rhythm Off J Heart Rhythm Soc. 2009;6(12 Suppl):S41-5. 
97. Saint LL, Lawrance CP, Okada S, Kazui T, Robertson JO, Schuessler RB, et al. Performance of a novel bipolar/monopolar radiofrequency ablation device on the beating heart in an acute porcine model. Innov Phila Pa. 2013;8:276-83.

98. Demazumder D, Mirotznik MS, Schwartzman D. Biophysics of radiofrequency ablation using an irrigated electrode. J Interv Card Electrophysiol. 2001;5: 377-89.

99. Kiser AC, Nifong LW, Raman J, Kasirajan V, Campbell N, Chitwood WR. Evaluation of a novel epicardial atrial fibrillation treatment system. Ann Thorac Surg. 2008;85:300-3.

100. Weimar T, Lee AM, Ray S, Schuessler RB, Damiano RJ. Evaluation of a novel cryoablation system: in vivo testing in a chronic porcine model. Innov Phila Pa. 2012; 7:410-6.

101. Milla F, Skubas N, Briggs WM, Girardi LN, Lee LY, Ko W, et al. Epicardial beating heart cryoablation using a novel argon-based cryoclamp and linear probe. J Thorac Cardiovasc Surg. 2006;131:403-11.
102. Ad N, Holmes SD. Prediction of sinus rhythm in patients undergoing concomitant Cox maze procedure through a median sternotomy. J Thorac Cardiovasc Surg. 2014;148:881-7.

103. Lee R, McCarthy PM, Wang EC, Vaduganathan M, Kruse J, Malaisrie SC, et al. Midterm survival in patients treated for atrial fibrillation: a propensity-matched comparison to patients without a history of atrial fibrillation. J Thorac Cardiovasc Surg. 2012;143:1341-51.

104. Whitlock R, Healey J, Vincent J, Brady K, Teoh K, Royse A, et al. Rationale and design of the Left Atrial Appendage Occlusion Study (LAAOS) III. Ann Cardiothorac Surg. 2014;3:45-54.

105. Gillinov AM, Saltman AE. Ablation of atrial fibrillation with concomitant cardiac surgery. Semin Thorac Cardiovasc Surg. 2007;19:25-32.

106. Warnes CA, Williams RG, Bashore TM, Child JS, Connolly HM, Dearani JA, et al. ACC/AHA 2008 Guidelines for the management of adults with congenital heart disease: executive summary. Circulation. 2008;118: 2395-451. 
TABLE E1. PubMed search terms used for research questions evaluated by meta-analytic or systematic review methodology

\section{Research question search terms}

\#1: Perioperative Morbidity

(((c"atrial fibrillation” OR “AF” OR “afib”) AND (“surgical ablation” OR "Maze” OR "Cox-Maze” OR "Cox maze” OR "ablation” OR "pulmonary vein isolation" OR "afib ablation" OR (afib AND ("therapy”[Subheading] OR "therapy" OR "treatment" OR "therapeutics” [MeSH Terms] OR "therapeutics")) OR "af ablation" OR "persistent af ablation”)) AND ("cardiac surgery" OR "heart surgery" OR "surgery" OR "surgical" OR "median sternotomy" OR "mid-sternotomy" OR "mid sternotomy" OR “mid sternum" OR "minimally invasive" OR "right thoracotomy")) AND ("survival" OR “mortality" OR "death")

\#2: Stroke/TIA

((“cardiac surgery" OR "heart surgery" OR "surgery" OR "surgical” OR "median sternotomy" OR "mid-sternotomy" OR "mid sternotomy" OR "mid sternum" OR "minimally invasive" OR "right thoracotomy”) AND ("surgical ablation" OR "Maze" OR "Cox-Maze" OR "Cox maze" OR "ablation" OR "pulmonary vein isolation" OR "afib ablation" OR "afib treatment" OR "af ablation" OR "persistent af ablation") AND ("atrial fibrillation" OR "AF” OR "afib”) AND ("stroke" OR "embolic stroke” OR “embolic event" OR "TIA" OR "transient ischemic attack" OR transient ischaemic attack" OR "cerebrovascular accident" OR "CVA" OR “cerebrovascular insult" OR "CVI”))

\#3: Quality of Life

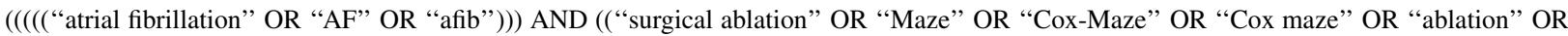
"pulmonary vein isolation” OR "afib ablation" OR (afib AND ("therapy”[Subheading] OR "therapy” OR "treatment" OR "therapeutics”[MeSH Terms] OR "therapeutics")) OR "af ablation" OR "persistent af ablation”))) ) AND (("cardiac surgery" OR "heart surgery" OR "surgery" OR "surgical” OR "median sternotomy" OR "mid-sternotomy" OR "mid sternotomy" OR "mid sternum" OR "minimally invasive” OR "right thoracotomy"))) AND (("HRQL" OR "health-related quality of life" OR "quality of life" OR "QOL" OR "health related quality of life" OR "SF-12" OR "Short Form 12" OR "SF-36" OR "Short Form 36"))

\#4: Survival

(((c“atrial fibrillation” OR “AF” OR “afib”) AND (“surgical ablation” OR “Maze” OR “Cox-Maze” OR "Cox maze” OR "ablation” OR "pulmonary vein isolation" OR "afib ablation" OR (afib AND ("therapy”[Subheading] OR "therapy” OR "treatment” OR "therapeutics” [MeSH Terms] OR "therapeutics”)) OR "af ablation" OR "persistent af ablation”)) AND ("cardiac surgery" OR "heart surgery" OR "surgery" OR "surgical" OR "median sternotomy" OR "mid-sternotomy" OR "mid sternotomy" OR “mid sternum" OR "minimally invasive" OR "right thoracotomy")) AND ("survival" OR "mortality" OR "death") 